Chemical Technology Division

\title{
AN EVALUATION OF A DUAL CORIOLIS METER SYSTEM FOR IN-LINE MONITORING OF SUSPENDED SOLIDS CONCENTRATIONS IN RADIOACTIVE SLURRIES
}

T. D. Hylton

September 2000

Prepared by OAK RIDGE NATIONAL LABORATORY

Oak Ridge, Tennessee 37831-6285

operated by

UT-BATTELLE, LLC

for the

U.S. DEPARTMENT OF ENERGY

under contract DE-AC05-00OR22725 



\section{CONTENTS}

LIST OF FIGURES $\ldots \ldots \ldots \ldots \ldots \ldots \ldots \ldots \ldots \ldots \ldots \ldots \ldots \ldots \ldots \ldots$

LIST OF TABLES $\ldots \ldots \ldots \ldots \ldots \ldots \ldots \ldots \ldots \ldots \ldots \ldots \ldots \ldots \ldots \ldots \ldots \ldots \ldots \ldots \ldots$

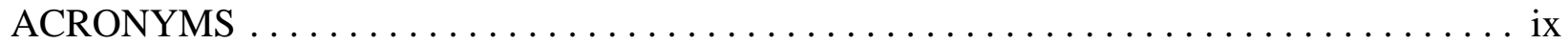

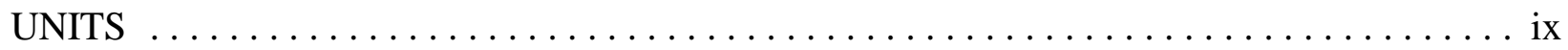

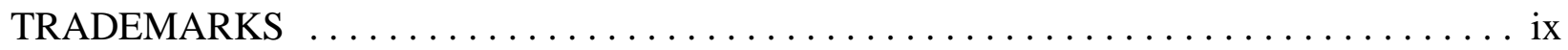

ACKNOWLEDGMENTS $\ldots \ldots \ldots \ldots \ldots \ldots \ldots \ldots \ldots \ldots \ldots \ldots \ldots \ldots \ldots \ldots \ldots$

EXECUTIVE SUMMARY $\ldots \ldots \ldots \ldots \ldots \ldots \ldots \ldots \ldots \ldots \ldots \ldots \ldots \ldots \ldots \ldots \ldots \ldots$

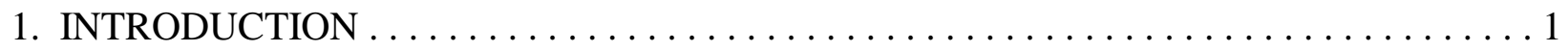

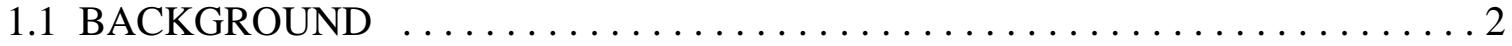

2. DESCRIPTION OF SITE, EQUIPMENT, AND INSTRUMENTATION $\ldots \ldots \ldots \ldots \ldots . .4$

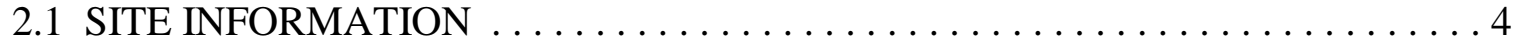

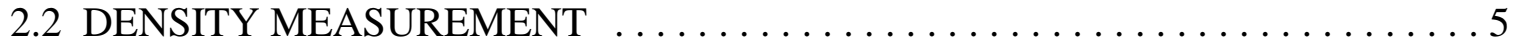

2.3 CONCENTRATION OF SUSPENDED SOLIDS $\ldots \ldots \ldots \ldots \ldots \ldots \ldots \ldots .8$

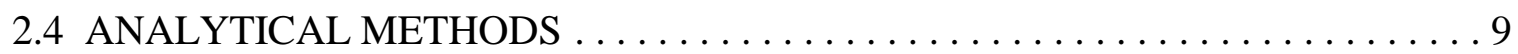

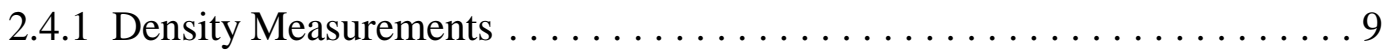

2.4.2 Concentration of Total Suspended Solids . . . . . . . . . . . . . 10

2.5 DATA COLLECTION AND EVALUATION $\ldots \ldots \ldots \ldots \ldots \ldots \ldots \ldots \ldots \ldots$

3. ANALYTICAL RESULTS AND DATA EVALUATION $\ldots \ldots \ldots \ldots \ldots \ldots \ldots \ldots \ldots$

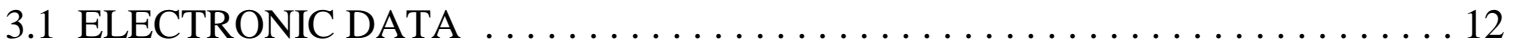

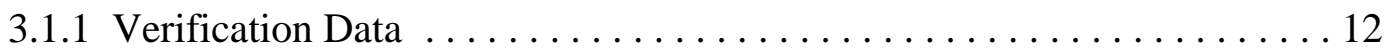

3.1 .2 Long-Term Data . . . . . . . . . . . . . . . . . . . 12

3.2 COMPARISON WITH SUSPENDED SOLIDS ANALYSIS $\ldots \ldots \ldots \ldots \ldots \ldots$

3.3 SUSPENDED SOLIDS CONCENTRATION FROM LABORATORY

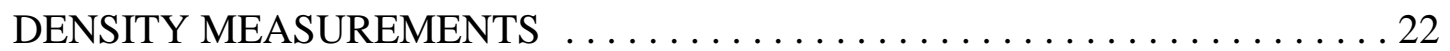

3.4 TEMPERATURE ADJUSTMENT OF DENSITY DATA $\ldots \ldots \ldots \ldots \ldots \ldots . \ldots 24$

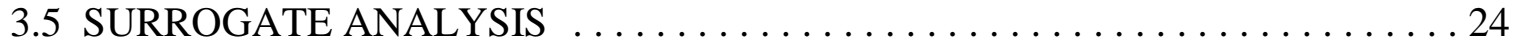

4. CONCLUSIONS AND RECOMMENDATIONS . . . . . . . . . . . . . . . 29

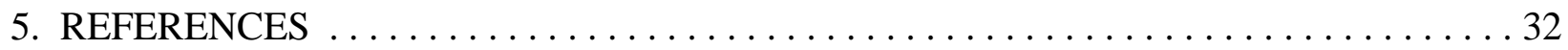

Appendix A. CALCULATION OF SUSPENDED SOLIDS FROM DENSITY DATA

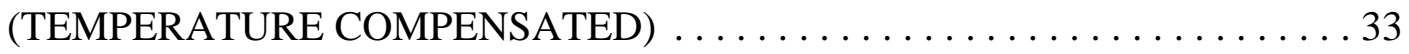

Appendix B. LETTER OF RESPONSE FROM ENDRESS + HAUSER . . . . . . . . . 37 



\section{LIST OF FIGURES}

Figure $\quad \underline{\text { Page }}$

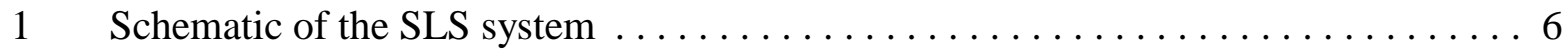

2 Photograph of the Endress + Hauser Promass 63F Coriolis meter installed in its

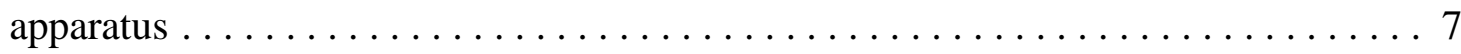

3 Plot of suspended solids concentration (left axis) and density (right axis) data obtained with the two Coriolis meters for the nominal 6 wt $\%$ sample. The suspended solids concentration data are determined from the density data . . . 13

4 Plot of suspended solids concentration (left axis) and density (right axis) data obtained with the two Coriolis meters for the nominal $8 \mathrm{wt} \%$ sample. The suspended solids concentration data are determined from the density data $\ldots 14$

5 Plot of slurry and filtrate temperatures for the 30-min evaluation period for the

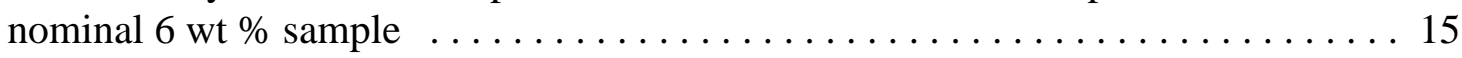

6 Plot of slurry and filtrate temperatures for the 30-min evaluation period for the

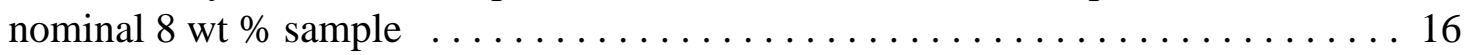

7 Comparison of suspended solids concentration determined by laboratory analysis with that obtained by using dual Coriolis meters . . . . . . . . . . . . 20

8 Comparison of density data determined by laboratory analysis with that obtained

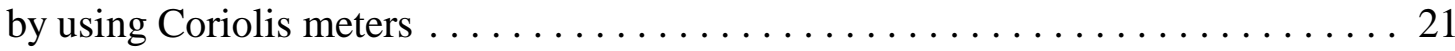

9 Comparison of suspended solids concentration determined from density data obtained by laboratory analysis with the suspended solids concentration

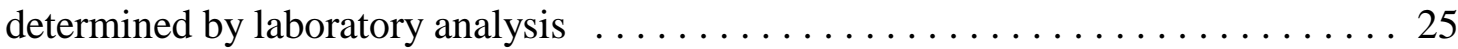

10 Comparison of suspended solids concentration determined from laboratory measurement of density (after adjustment due to temperature difference) with

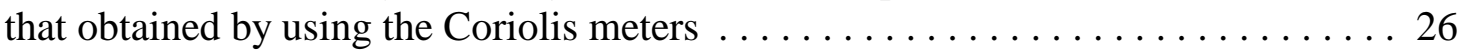





\section{LIST OF TABLES}

Table

1 Data obtained with the dual Coriolis meter system over a 30 -min period $\ldots \ldots \ldots 12$

2 Comparison of density data collected with the Coriolis meters as a

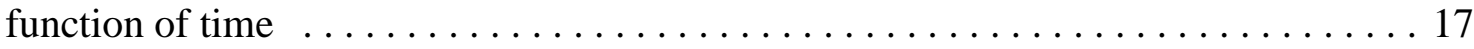

3 Comparison of results from grab samples with those obtained by using dual Coriolis meters . . . . . . . . . . . . . . . . . . . . . . . 19

$4 \quad$ Suspended solids concentration determined from density measurements from laboratory analysis as compared with the results obtained by using the

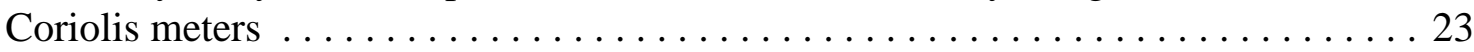

5 Physical property data for surrogate samples $\ldots \ldots \ldots \ldots \ldots \ldots \ldots \ldots \ldots \ldots$

6 Surrogate sample results and data analyses $\ldots \ldots \ldots \ldots \ldots \ldots \ldots \ldots \ldots \ldots$ 



\section{ACRONYMS}

ASTD Accelerated Site Technology Deployment

CMST-CP Characterization, Monitoring, and Sensor Technology Crosscutting Program

DOE U.S. Department of Energy

MVSTs Melton Valley Storage Tanks

ORNL Oak Ridge National Laboratory

SLS solid-liquid separation

TFA Tanks Focus Area

TDS total dissolved solids

TS total solids

TSS total suspended solids

$\begin{array}{ll}\mathrm{ft} & \text { foot } \\ \mathrm{g} & \text { gram } \\ \mathrm{gal} & \text { gallon } \\ \mathrm{gpm} & \text { gallon per minute } \\ \mathrm{L} & \text { liter } \\ \mathrm{mg} & \text { milligram } \\ \mathrm{mL} & \text { milliliter } \\ \mathrm{wt} \% & \text { weight percent } \\ { }^{\circ} \mathrm{C} & \text { degrees Celsius }\end{array}$

\section{UNITS}

\section{TRADEMARKS}

Isolok Registered trademark of Bristol Engineering Company, Yorkville, Illinois. Lasentec Registered trademark of Laser Sensor Technology, Inc., Redmond, Washington. Promass Registered trademark of Endress + Hauser Flowtec AG Corporation, Reinach, Switzerland. 



\section{ACKNOWLEDGMENTS}

This project was jointly sponsored by the U.S. Department of Energy's Characterization, Monitoring, and Sensor Technology Crosscutting Program (CMST-CP) and Tanks Focus Area (TFA) through Technical Task Plan OR-17C231, CCADS 3TFR. The CMST-CP and the TFA are programs within the Office of Science and Technology.

The success of this project can be attributed to the cooperation of many individuals and organizations. In addition to the sponsors, the author would like to express his appreciation to several individuals and organizations for their contributions, as follows.

The CMST-CP's project facilitator was W. J. Haas, Jr. The progress of the project was closely monitored by T. R. Thomas and G. J. Bastiaans, representatives of the TFA and CMST-CP, respectively. The DOE field office program managers were D. D. Green and J. R. Noble-Dial.

Personnel who made technical contributions include the following: J. R. Farmer, Lockheed Martin Energy Systems Engineering Division, for design support in installing the filtrate Coriolis meter in the solid-liquid separation system; M. T. Hurst and D. G. Raby, of the ORNL Instrumentation and Controls Division, for integrating the instrumentation into the data acquisition system; J. M. Giaquinto and D. L. Denton, of the ORNL Chemical and Analytical Sciences Division, for analyzing the grab samples; C. K. Bayne, ORNL Computer Science and Mathematics Division, for statistical guidance; and M. G. Stewart for providing editorial services. A special thanks goes to the personnel who collected the data and grab samples during operation of the Wastewater Triad Project. 



\section{EXECUTIVE SUMMARY}

The U.S. Department of Energy (DOE) has millions of gallons of radioactive liquid and sludge wastes stored in underground tanks at several of its sites. In order to comply with various regulations and to circumvent potential problems associated with tank integrity, these wastes must be retrieved from the tanks, transferred to treatment facilities (or other storage locations), and processed to stable waste forms. The sludge wastes will typically be mobilized by some mechanical means (e.g., mixer pump, submerged jet) and mixed with the respective supernatants to create slurries that can be transferred by pipeline to the desired destination. Depending on the DOE site, these slurries may be transferred up to six miles.

Since the wastes are radioactive, it is critically important for the transfers to be made without plugging a pipeline. To reduce such a risk, the relevant properties of the slurry (e.g., density, suspended solids concentration, viscosity, and particle size distribution) should be determined to be within acceptable limits prior to transfer. These properties should also be continuously monitored and controlled within specified limits while the transfer is in progress.

The baseline method for determining the transport properties of slurries involves sampling and analysis; however, this method is time-consuming, and costly, and it does not provide real-time information. In addition, personnel who collect and analyze the samples are exposed to radiation. It is also questionable as to whether a laboratory analyst can obtain representative aliquots from the sample jar for these solid-liquid mixtures.

The alternative method for determining the transport properties is in-line analysis. An in-line instrument is one that is connected to the process, analyzes the slurry as it flows through or by the instrument, and provides the results within seconds. This instrument can provide immediate feedback to operators so that, when necessary, the operators can respond quickly to counteract conditions that could lead to pipeline pluggage (e.g., backflushing the pipeline with water).

One of the highest priorities is to determine the concentration of suspended solids in each of the slurries. In the project described in this report, two Coriolis meters were used simultaneously to create a suspended solids monitoring system that would provide accurate results with high precision. One Coriolis meter was used to measure the density of the slurry, while the other meter was used to measure the density of the carrier fluid (i.e., after filtration to 
remove the solid particles). The suspended solids concentration was then calculated from the density relationships between the slurry, the carrier fluid, and the dry solid particles. The latter density was determined by laboratory analysis and was assumed to be constant throughout the periods that grab samples were collected.

A dual Coriolis meter system was installed at Oak Ridge National Laboratory to monitor the concentrations of suspended solids in radioactive slurries for the solid-liquid separation system. Grab samples were also collected and analyzed to verify the results obtained with the dual meters. The results showed that the concentrations of suspended solids as reported by the dual Coriolis meter system tended to be slightly higher than those obtained from laboratory analysis. This difference is likely attributable to the sensitivity of the equation for calculating suspended solids concentration to variation in the slurry density and/or filtrate density. The precision (or repeatability) of the Coriolis meters was very good. Each of the meters had a standard deviation of $\leq 0.0005 \mathrm{~g} / \mathrm{mL}$ for the density. The standard deviation of the suspended solids concentration determined with the dual instruments was $0.08 \mathrm{wt} \%$. These results are quite good when one considers that the densities of the slurries were 0.01 to $0.05 \mathrm{~g} / \mathrm{mL}$ greater than those of the filtrates. 


\section{AN EVALUATION OF A DUAL CORIOLIS METER SYSTEM FOR IN-LINE MONITORING OF SUSPENDED SOLIDS CONCENTRATIONS IN RADIOACTIVE SLURRIES}

\section{INTRODUCTION}

The U.S. Department of Energy (DOE) has millions of gallons of radioactive liquid and sludge wastes stored in underground tanks at several of its sites, such as Hanford, Savannah River, and Oak Ridge. In order to comply with various regulations and to circumvent potential problems associated with tank integrity, these wastes must be retrieved from the underground tanks, transferred to treatment facilities (or other storage location), and processed to a stable waste form. Each sludge waste will typically be mobilized by some mechanical means (e.g., mixer pump, submerged jet) and mixed with the supernatant to create a slurry that can be transferred by pipeline to the desired destination. Depending on the DOE site, such slurries may be transferred up to six miles.

Since these wastes are radioactive, it is critically important that the transfers be conducted safely and successfully. The transport properties of a given slurry must be within the appropriate design limits to prevent the formation of a pipeline plug. The consequences of a plugged pipeline with radioactive material are unacceptable from the perspectives of safety, cost, and schedule. If a pipeline plug occurs and conventional methods (e.g., water flushing) are not successful, either the entire pipeline must be replaced (and the plugged pipeline remediated at a later date) or the plugged sections must be located, excised, and replaced. Either option would expose workers to radiation fields, and the cost of the project could escalate and result in a severe delay of the project schedule. Even if a pipeline plug were successfully removed by conventional methods, the project would experience some delay and additional costs. For example, flushing a plugged pipeline would require a shutdown of operations until the situation could be resolved; and such action would lead to the generation of additional liquid waste, which would also require treatment.

To reduce the risk of plugging a pipeline, the relevant properties of the slurry (e.g., density, suspended solids concentration, viscosity, and particle size distribution) should be determined to be within acceptable limits prior to transfer. These properties should also be 
continuously monitored and controlled within specified limits while the slurry transfer is in progress.

The baseline method for determining the transport properties of slurries involves sampling and analysis. This method is time-consuming and costly, and it does not provide real-time information. In addition, the personnel who collect and analyze the samples are exposed to radiation. It is also questionable as to whether a laboratory analyst can obtain representative aliquots from the solid-liquid mixtures in the sample jar.

The alternative method for determining the transport properties is in-line analysis. An inline instrument is one that is connected to the process, analyzes the slurry as it flows through or by the instrument, and provides the results within seconds. This instrument can provide immediate feedback to operators so that, when necessary, the operators can respond quickly to counteract conditions that could lead to pipeline plugging (e.g., backflushing the pipeline with water).

\subsection{BACKGROUND}

In 1995, DOE issued a call for proposals for developing in-line instrumentation to measure the transport properties of slurries. At that time, it was believed that either commercial instrumentation was not available or the existing commercial instrumentation would not work properly in the needed radioactive applications. In response to the call, several researchers from various DOE facilities submitted proposals and received funding to develop slurry monitoring instruments. Since these instruments were prototypes, DOE wanted to evaluate them with nonradioactive slurries to determine if they provided accurate and repeatable data and to confirm that they were reliable. In FY 1997, Oak Ridge National Laboratory (ORNL) evaluated these prototypes along with several commercially available instruments. Based on the results of the testing, ${ }^{1}$ the project sponsor selected the Endress + Hauser Promass ${ }^{\circledR} 63$ Coriolis meter (for measuring density) and a prototype ultrasonic monitor that was developed by Argonne National Laboratory (for measuring suspended solids concentration) as the best prospects for a demonstration with a radioactive application.

In FY 1999, a pipeline slurry monitoring system was installed and tested at the Gunite and Associated Tanks (GAAT) project at ORNL. This system included the selected instruments 
mentioned above, as well as a Lasentec ${ }^{\circledR}$ M600P instrument for monitoring the particle chord length distribution (a parameter that is related to particle size distribution) of solids in the slurries. The Lasentec M600P, which had previously been evaluated by Pacific Northwest National Laboratory, ${ }^{2-4}$ was included at the request of the Accelerated Site Technology Deployment (ASTD) Program. As a result of the test data, the Endress + Hauser 63M Coriolis meter and the Lasentec M600P were officially deployed by the GAAT Remediation Project for measuring the slurry density and particle chord length distribution, respectively. The prototype ultrasonic monitor for measuring suspended solids concentration was determined to be significantly affected by entrained air in the slurry and was not accepted for deployment. The density data obtained by the Promass 63M Coriolis meter were used to calculate the suspended solids concentration of the slurries with the assumption that the densities of the carrier fluid and the dry solid particles were known and constant. The results showed that the suspended solids concentration determined with this method was in relatively good agreement with the results obtained from grab sampling. ${ }^{5}$

For situations where the density of the carrier fluid is not constant, the accuracy in the suspended solids determination could be improved if the density of the carrier fluid could be determined simultaneously with the density of the slurry. Since the Promass 63M Coriolis meter had been shown to provide acceptable density data, it was conceived that a filtration system and a second Coriolis meter could be installed on a sidestream to monitor the density of the carrier fluid in line and in real time simultaneously with the density of the slurry. 


\section{DESCRIPTION OF SITE, EQUIPMENT, AND INSTRUMENTATION}

\subsection{SITE INFORMATION}

The Melton Valley Storage Tanks (MVSTs) are the primary liquid low-level waste collection vessels for long-term storage at ORNL. These tanks are essentially identical except for some minor piping differences. The MVSTs include eight tanks that are constructed from stainless steel and have a nominal capacity of $189 \mathrm{~m}^{3}$ (50,000 gal) each. They are horizontal cylinders with dished end caps; each tank has an overall length of $18.7 \mathrm{~m}(61.4 \mathrm{ft})$ and a diameter of $3.6 \mathrm{~m}(12 \mathrm{ft})$.

Since the tanks are constructed from stainless steel, the waste stored in them must be neutralized to a $\mathrm{pH}$ of 10-12 to prevent corrosion. After $\mathrm{pH}$ adjustment, solids that are no longer soluble precipitate out and, as a result, form sludge layers. At present, MVSTs are nearly filled with sludge and liquid wastes, with the sludge layers ranging from $\sim 2$ to $5 \mathrm{ft}$ deep.

ORNL desired to treat the liquid waste both for the removal of cesium and for volume reduction; however, the equipment to be used for these tasks would be fouled by the undissolved solids. Since the feed pipe from each tank is beneath the sludge layer, it was not possible to remove liquid from the tank without also removing undissolved solids. Therefore, ORNL installed a full-scale solid-liquid separation (SLS) system for the separation of undissolved solids from the liquid stream. The SLS, which is a modular cross-flow filtration system, contains sintered-metal tubes that have a surface area of $4.6 \mathrm{~m}^{2}\left(50 \mathrm{ft}^{2}\right)$ and a particle retention rating of $0.5 \mu \mathrm{m} .{ }^{6}$ After being treated by the SLS, the clean liquid was transferred to the cesium removal and volume reduction operations. The three unit operations are collectively referred to as the Wastewater Triad Project.

In order to prevent inadvertent plugging of the SLS system, the site operations originally installed an Endress + Hauser 63F Coriolis meter to monitor the density of each slurry mixture. The concentration of suspended solids was estimated based on the relationship between the densities of the slurry, the carrier fluid, and the dry undissolved solids (see Sect. 2.3). The density of the carrier fluid, which was obtained by grab sample analysis prior to beginning operations, was assumed to be constant. The density of the dry undissolved solids was assumed to be that typical for calcium carbonate (a principal component of the sludge) and was also assumed to be constant. These assumptions introduced some error in the determination of 
suspended solids, so the Wastewater Triad Project requested that a second Coriolis meter be installed to eliminate the assumption about the density of the carrier fluid being constant and thus improve the accuracy of the suspended solids determination. The use of the two Coriolis meters to determine the concentration of suspended solids by simultaneously determining the slurry density and the carrier fluid density will be referred to as a dual Coriolis meter system.

A schematic diagram for the SLS system is shown in Fig. 1. Each of the Coriolis meters is designated as "DM" in the drawing. Filtrate from the cross-flow filtration system was collected in a filtrate holding tank and then transferred for additional cesium removal and/or volume reduction in $300-\mathrm{L}$ (80-gal) batches. The filtrate was continuously recirculated to ensure that it was well mixed. An in-line sampler was included in the recirculation loop for obtaining grab samples. This recirculation loop was selected as the most feasible place to retrofit the second Coriolis meter to monitor the filtrate's density.

Since the SLS system was radioactively contaminated, the installation of the second Coriolis meter was carefully planned to reduce the potential of personnel contamination and radiation exposure. To accomplish this task, an Endress + Hauser Promass 63F Coriolis meter was procured and mounted in an apparatus as shown in Fig. 2. The apparatus was installed in the SLS by attaching it to the floor grating. Valving was included to permit bypassing the instrument in the unlikely event that it malfunctioned. If such an event occurred, operations personnel could bypass the instrument and continue treating the feed stream under the former scenario of assuming a constant value for the carrier fluid's density. Flexible tubing was used to reduce the time, and thus the radiation exposure, required for installing it in the SLS.

Discussion and details of the operation of the Wastewater Triad Project are outside the scope of this report, but additional information is available in several technical reports. ${ }^{6-8}$

\subsection{DENSITY MEASUREMENT}

The Promass 63F Coriolis meter splits the flow of the slurry (or liquid) through two tubes that are always made to oscillate at their resonant frequency. The excitation frequency is adjusted automatically when the mass, and therefore the density, of the oscillating system 


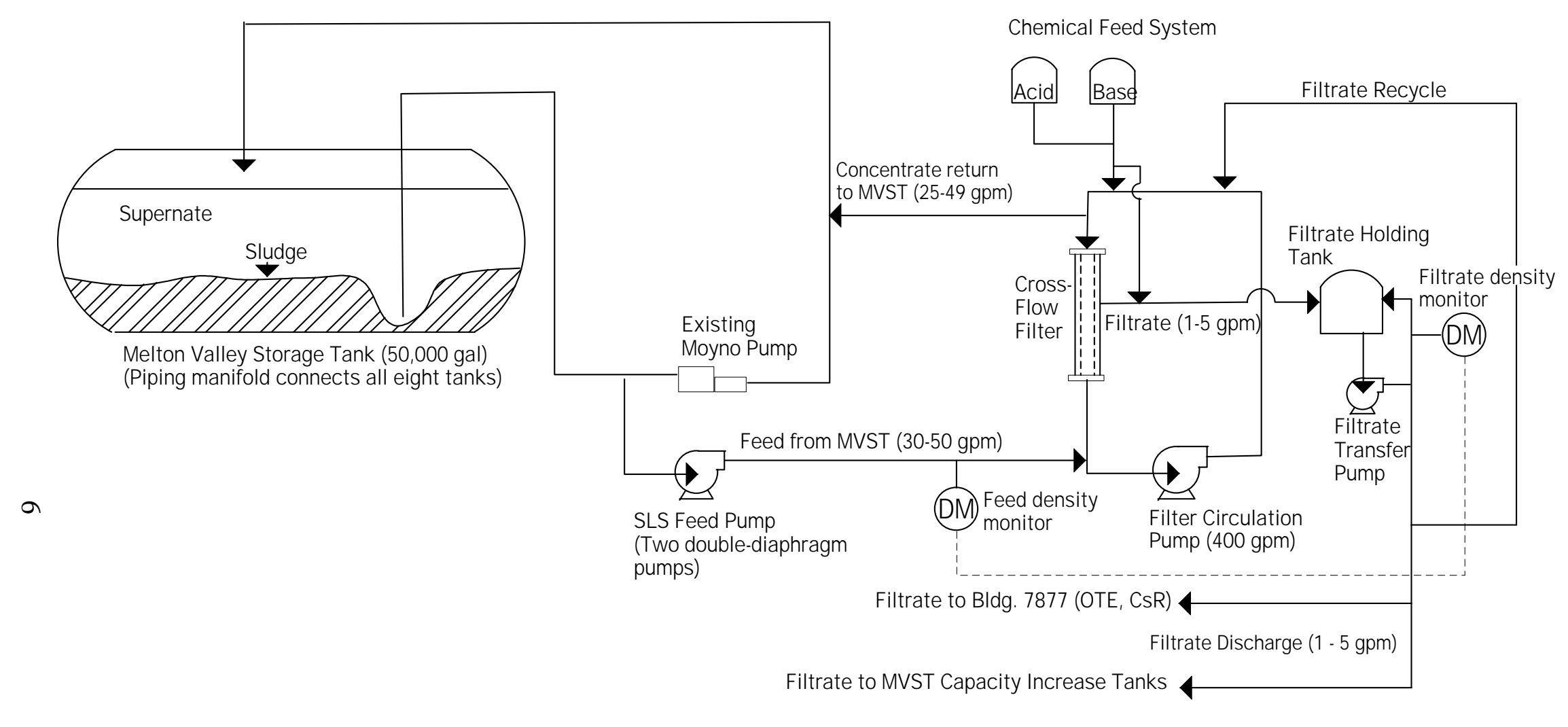

Fig. 1. Schematic of the SLS system. 


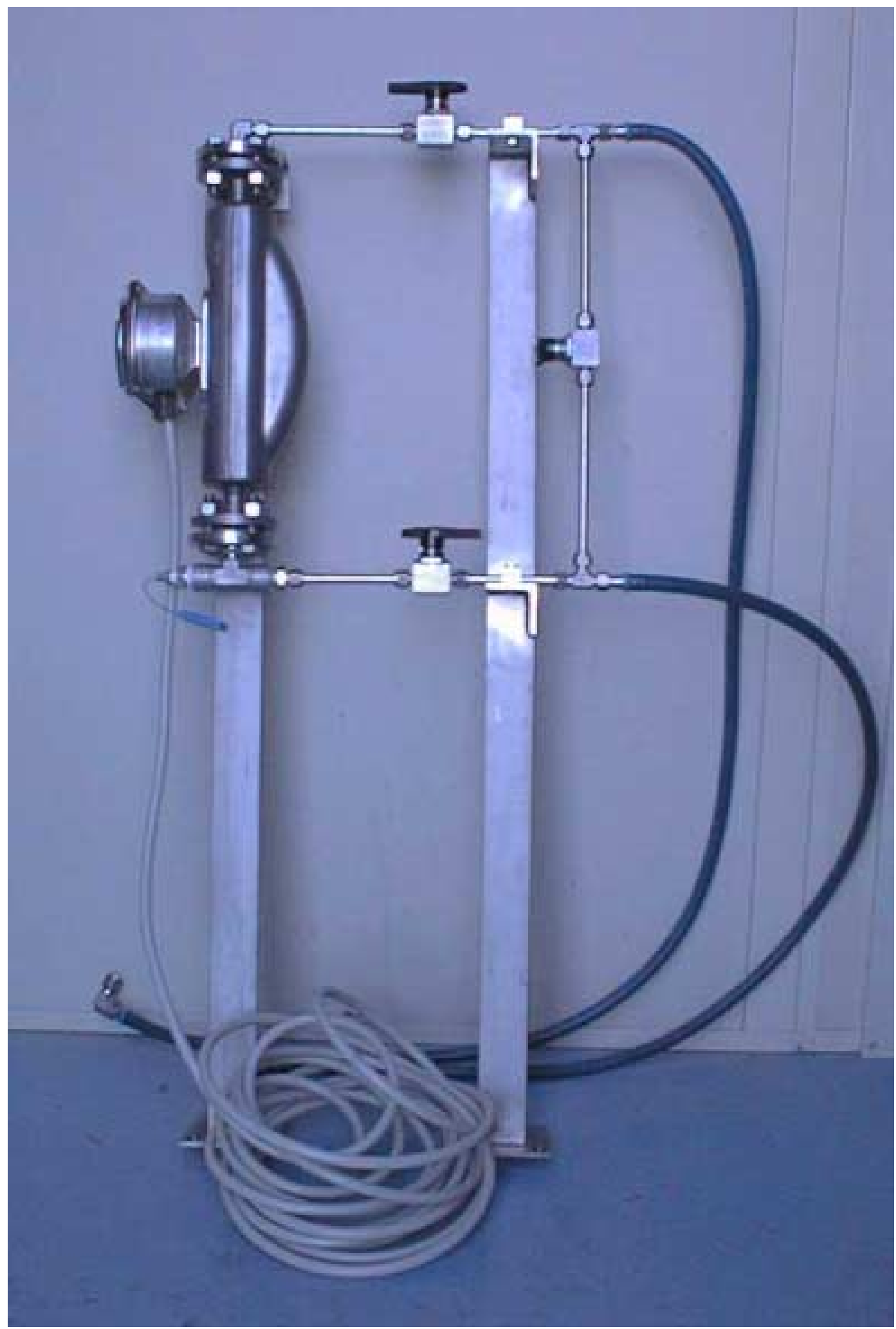

Fig. 2. Photograph of the Endress + Hauser Promass 63F Coriolis meter installed in its apparatus. 
changes (measuring tubes and medium). Thus, the resonant frequency is a function of the density of the medium and enables the microprocessor to produce a density signal.

\subsection{CONCENTRATION OF SUSPENDED SOLIDS}

By using the functions for two-phase media, it is possible to calculate the concentration (mass or volume) of the target medium in the carrier fluid. The basic formulas, which do not include temperature compensation, are

$$
\operatorname{Mass} \%=\frac{D 2 \times(\rho-D 1)}{\rho \times(D 2-D 1)} \times 100
$$

and

$$
\text { Volume } \%=\frac{(\rho-D l)}{(D 2-D l)} \times 100
$$

where

$$
\begin{aligned}
\rho & =\text { measured density of mixture, } \\
D 1 & =\text { density of carrier fluid (e.g., filtrate), } \\
D 2 & =\text { density of target material (e.g., dry undissolved solids). }
\end{aligned}
$$

These equations are derived from the definitions of density (mass/volume) and percent solids, with the assumption that both the respective masses and the volumes of the liquid and solid are additive. Depending on the mixture that is being analyzed, temperature may also have an effect on the determination of the suspended solids concentration. Equations for calculating the suspended solids concentration from density and include temperature compensation are shown in Appendix A. These equations require knowledge of the volume expansion coefficients for both the carrier fluid and the target material. Volume expansion coefficients are not typically known for DOE wastes, so Eqs. (1) and (2) are used to estimate the concentration.

The use of Eqs. (1) and (2) with a dual Coriolis meter system still requires that the density of the target material (e.g., the undissolved solids) be known and that it remains constant. The effect of the $D 2$ variable can be examined by a sensitivity analysis. For example, assume that a 
slurry with a density $(\rho)$ of $1.04 \mathrm{~g} / \mathrm{mL}$ is being transferred and that the carrier fluid has a density (D1) of $1.02 \mathrm{~g} / \mathrm{mL}$. For $D 2$ values of $2.1,2.3$, and $2.5 \mathrm{~g} / \mathrm{mL}$, the corresponding suspended solids concentrations are $3.74,3.46$, and $3.25 \mathrm{wt} \%$.

The densities of the slurry and carrier fluid must be determined accurately to at least the third decimal place to detect minor concentration changes. For example, assume that a slurry with $\rho=1.040 \mathrm{~g} / \mathrm{mL}, D 1=1.020 \mathrm{~g} / \mathrm{mL}$, and $D 2=2.500 \mathrm{~g} / \mathrm{mL}$ is being transferred. The suspended solids concentration for these conditions was previously reported to be $3.25 \mathrm{wt} \%$. If one assumes that the slurry density increases to $1.045 \mathrm{~g} / \mathrm{mL}$ while the carrier fluid's density remains constant, then the concentration of suspended solids would be $4.04 \mathrm{wt} \%$. This example illustrates that small changes in the slurry density can make the concentration of suspended solids change rapidly.

\subsection{ANALYTICAL METHODS}

\subsubsection{Density Measurements}

The densities of the slurry and filtrate grab samples were determined in accordance with a modified standard procedure D70-97, which was issued by the American Society for Testing and Materials. ${ }^{9}$ The modifications included (1) using radioactive slurry and fluid samples rather than asphalt samples; (2) omitting steps 10.1-10.4 of the procedure which call for heating the samples; and (3) analyzing each sample at the same temperature at which it was collected and analyzed by the Coriolis meters.

The tare weight and volume capacity of the pycnometer, a special flask used in the procedure, were accurately measured. An aliquot of sample was added to the pycnometer, and the weight of the aliquot was determined by reweighing the pycnometer. The pycnometer, which is designed to facilitate removal of air, was then filled with a liquid of known density (e.g., water) and reweighed. The volume of the liquid used to fill the pycnometer was determined from its mass and density. The volume of the sample aliquot was determined by the difference between the total volume of the pycnometer and the volume of the fill liquid. The density of the sample was determined by dividing its mass by its volume. 


\subsubsection{Concentration of Total Suspended Solids}

Analyses to determine the total suspended solid (TSS) were performed by a standard method issued by the Environmental Protection Agency. Because the samples were radioactive, the procedure was modified for use with small aliquots in order to reduce radiation exposure to personnel. ${ }^{10}$ The TSS concentration was determined by obtaining a known-volume aliquot of the well-mixed sample, which was filtered to separate the dissolved and undissolved solids. The residue that was collected on the filter medium was dried at $103-105^{\circ} \mathrm{C}$ and then cooled in a desiccator and reweighed. The drying, cooling, and reweighing cycle was repeated until a constant weight was obtained (less than 0.5 -mg change). The concentration of TSS (in mg/L) was determined by comparing the weight of the dried residue with that of the original sample volume. The units were then converted to mass fraction by dividing the analytical result by the density of the sample.

\subsection{DATA COLLECTION AND EVALUATION}

The use of two Coriolis meters in combination was evaluated by continuously monitoring the slurry feed to and the filtrate produced by the SLS system. The SLS system was operated under normal conditions, and the slurry and filtrate were analyzed as they existed in the pipeline.

Samples were collected using Isolok® sampling equipment. Sample tubing for the feed and filtrate was connected to each sampler from high- and low-pressure taps on the system from which a real-time sample was obtained. The Isolok sampler operates by extending a plunger with a cavity into the stream. When the plunger is retracted, the liquid (or slurry) drains into the sample jar. Each stroke of the plunger retrieves a 10-mL sample.

Three sets of samples were collected to verify the results reported by the dual Coriolis meter system. Feed and filtrate samples were obtained when the monitoring system indicated that the nominal concentrations were 2,6 , and $8 \mathrm{wt} \%$. The slurry was analyzed for both density and TSS, while the filtrate was analyzed for density only. The outputs from the Coriolis meters were connected to the data acquisition and control computer for the SLS system. The computer used the density data from the two Coriolis meters and calculated the concentration of suspended solids in the feed stream by using Eq. (1). The density of the dry, undissolved solids was assumed to remain constant. 
Electronic data were recorded continuously at 1-min intervals. The data for comparison with the grab samples were taken $15 \mathrm{~min}$ prior to and $15 \mathrm{~min}$ after the sample collection. The concentration of suspended solids reported by the dual Coriolis meter system was determined by the arithmetic average of the 30 data points. The precision (or repeatability) of the instrument was determined from the standard deviation of those data. Electronic data were collected for comparison with the nominal 6 and $8 \mathrm{wt} \%$ verification samples. Electronic data were not collected for the nominal $2 \mathrm{wt} \%$ sample because of a computer malfunction; however, pertinent data for the sample were recorded in a logbook by the operator when the sample was collected, and those data were used in lieu of electronic data. 


\section{ANALYTICAL RESULTS AND DATA EVALUATION}

\subsection{ELECTRONIC DATA}

\subsubsection{Verification Data}

The results for suspended solids concentration obtained with the dual Coriolis meter system for the 30-min evaluation periods are summarized in Table 1. Figures 3 and 4 are plots of suspended solids concentration data from the nominal 6 and $8 \mathrm{wt} \%$ verification samples versus time for the 30-min evaluation period, respectively. The slurry and filtrate densities are also plotted in these figures (right axes) for comparison purposes. Figures 5 and 6 show the slurry and filtrate temperatures for the nominal 6 and $8 \mathrm{wt} \%$ verification samples, respectively.

Table 1. Data obtained with the dual Coriolis meter system over a 30-min period

\begin{tabular}{|c|c|c|c|c|c|}
\hline \multicolumn{2}{|c|}{ Suspended solids concentration (wt \%) } & \multicolumn{2}{|c|}{ Slurry density $(\mathrm{g} / \mathrm{mL})$} & \multicolumn{2}{|c|}{ Filtrate density $(\mathrm{g} / \mathrm{mL})$} \\
\hline Average & Std. dev. & Average & Std. dev. & Average & Std. dev. \\
\hline $6.29^{a}$ & 0.07 & 1.0573 & 0.0004 & 1.0205 & 0.0002 \\
\hline $8.15^{b}$ & 0.08 & 1.0717 & 0.0005 & 1.0221 & 0.0001 \\
\hline
\end{tabular}

${ }^{a}$ The density of the undissolved solids was determined to be $2.289 \mathrm{~g} / \mathrm{mL}$ by laboratory analysis.

${ }^{b}$ The density of the undissolved solids was determined to be $2.360 \mathrm{~g} / \mathrm{mL}$ by laboratory analysis.

\subsubsection{Long-Term Data}

Operating personnel must have confidence that the solids monitoring system provides repeatable data over the long term. In addition to the electronic data collected for comparison with grab samples, electronic data were also collected at periods when grab samples were not taken. Table 2 shows the results for both the slurry-monitoring meter and the filtrate-monitoring meter. These data were taken primarily during periods when the concentration of suspended solids and the temperatures were relatively constant. Some of the data were recorded when there was no flow in the system, but the Coriolis meters were filled with liquid or slurry. In some cases the data are for water rather than slurry or filtrate (identifiable by the density). The electronic data were recorded at 1-min intervals. Table 2 shows the average and standard deviation values for density, temperature, and mass flow for both Coriolis meters for the selected time periods. 


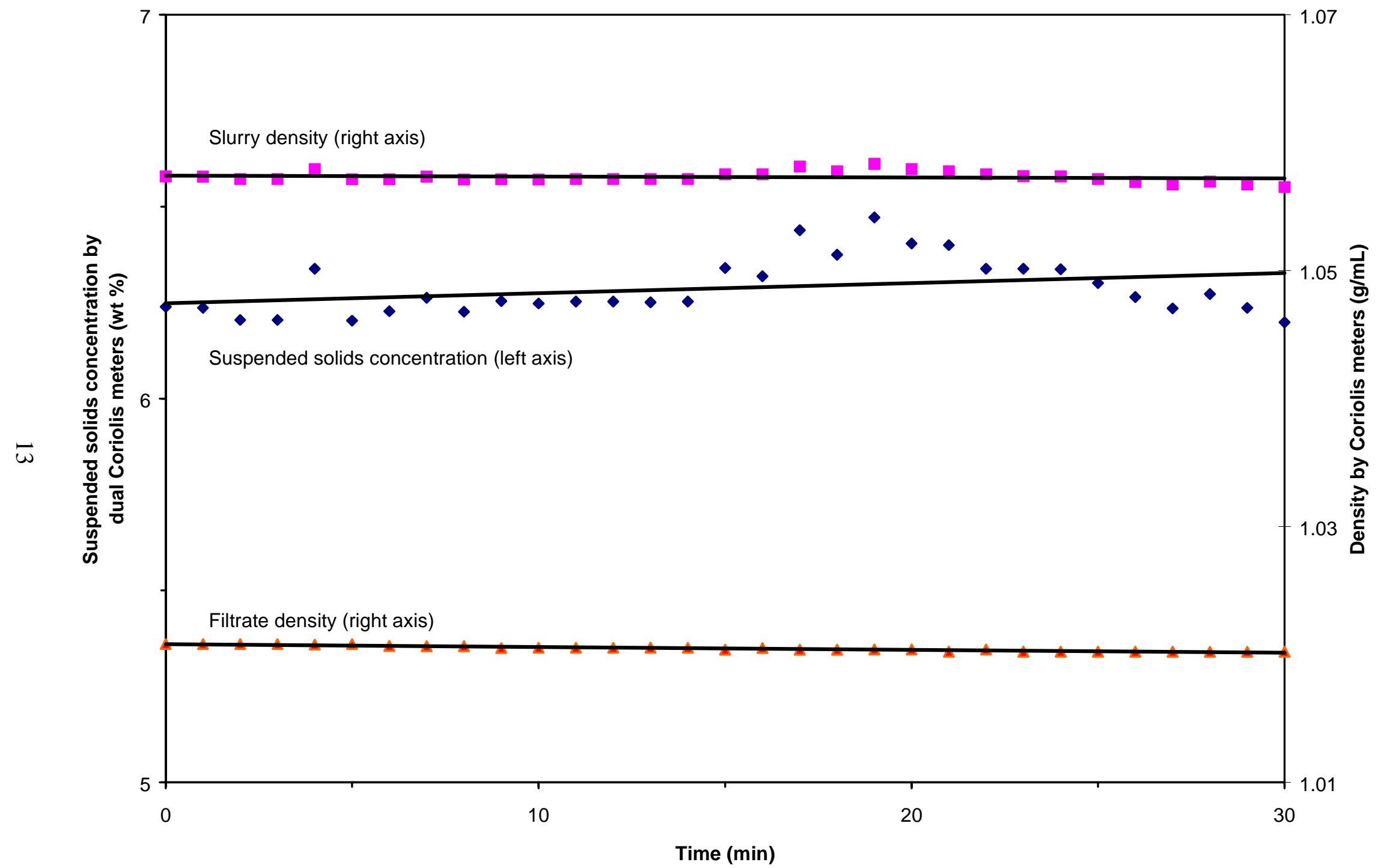

Fig. 3. Plot of suspended solids concentration (left axis) and density (right axis) data obtained with the two Coriolis meters for the nominal $6 \mathrm{wt} \%$ sample. The suspended solids concentration data are determined from the density data. 


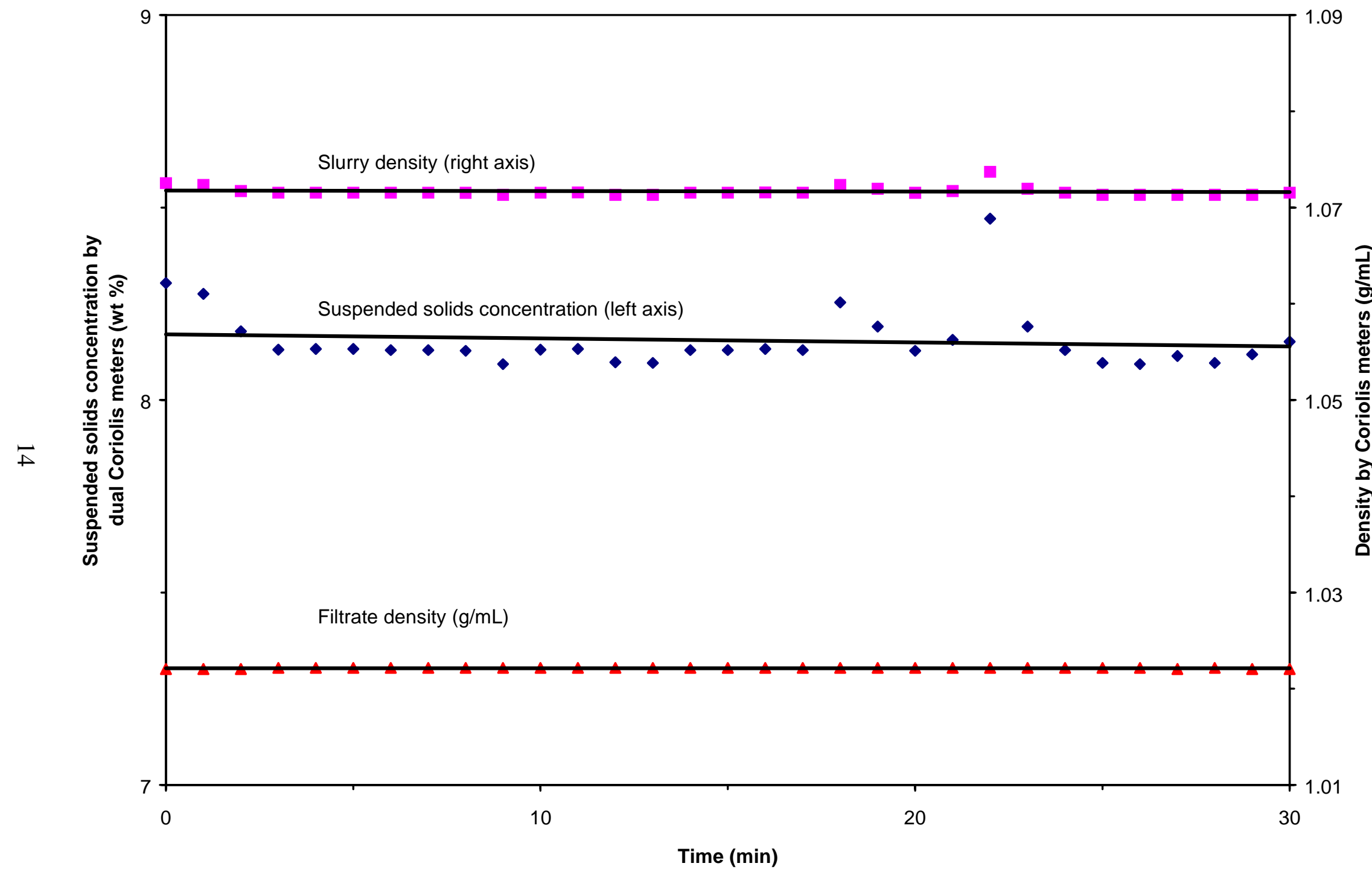

Fig. 4. Plot of suspended solids concentration (left axis) and density (right axis) data obtained with the two Coriolis meters for the nominal $8 \mathrm{wt} \%$ sample. The suspended solids concentration data are determined from the density data. 


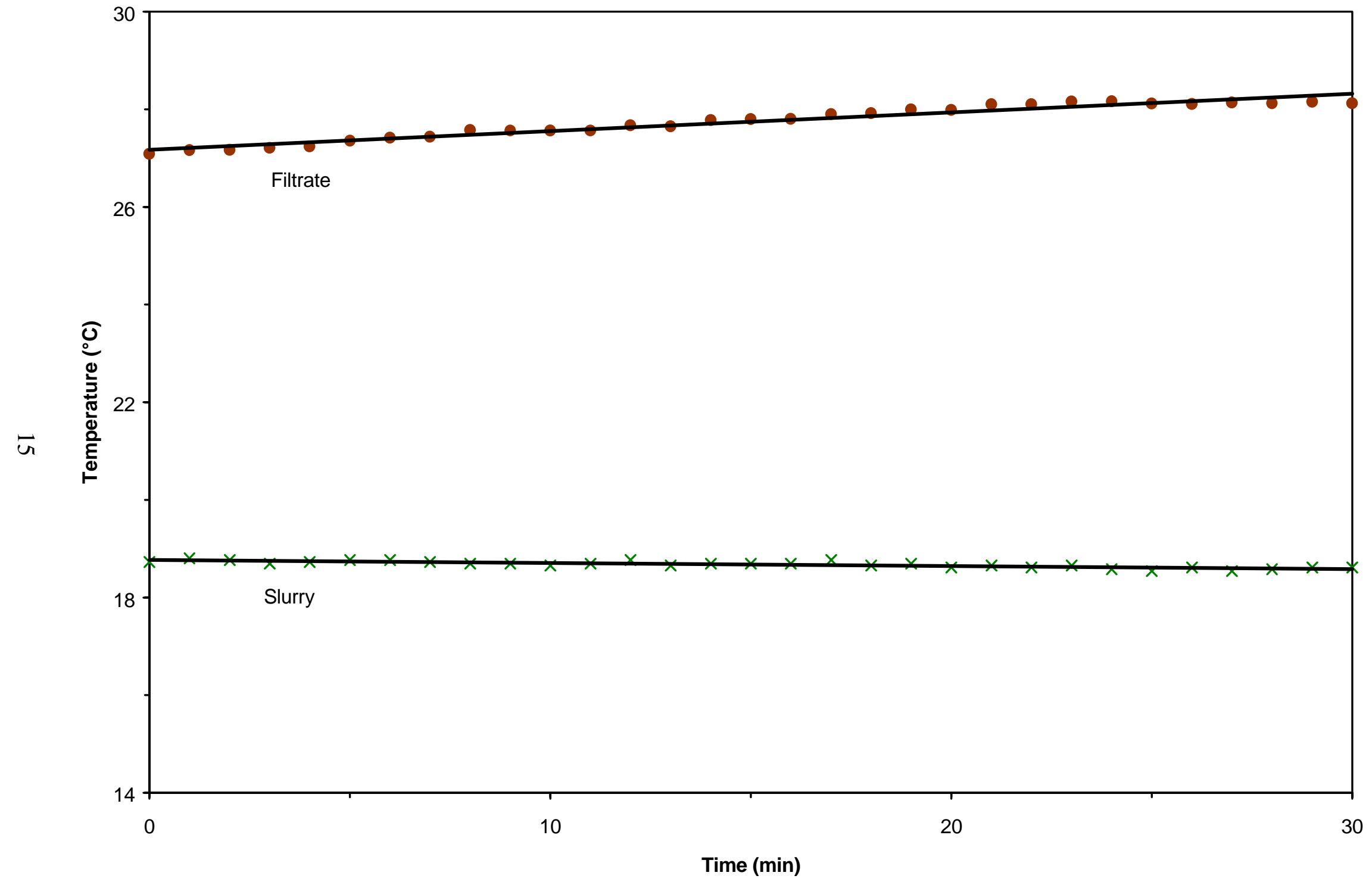

Fig. 5. Plot of slurry and filtrate temperatures for the 30-min evaluation period for the nominal 6 wt $\%$ sample. 


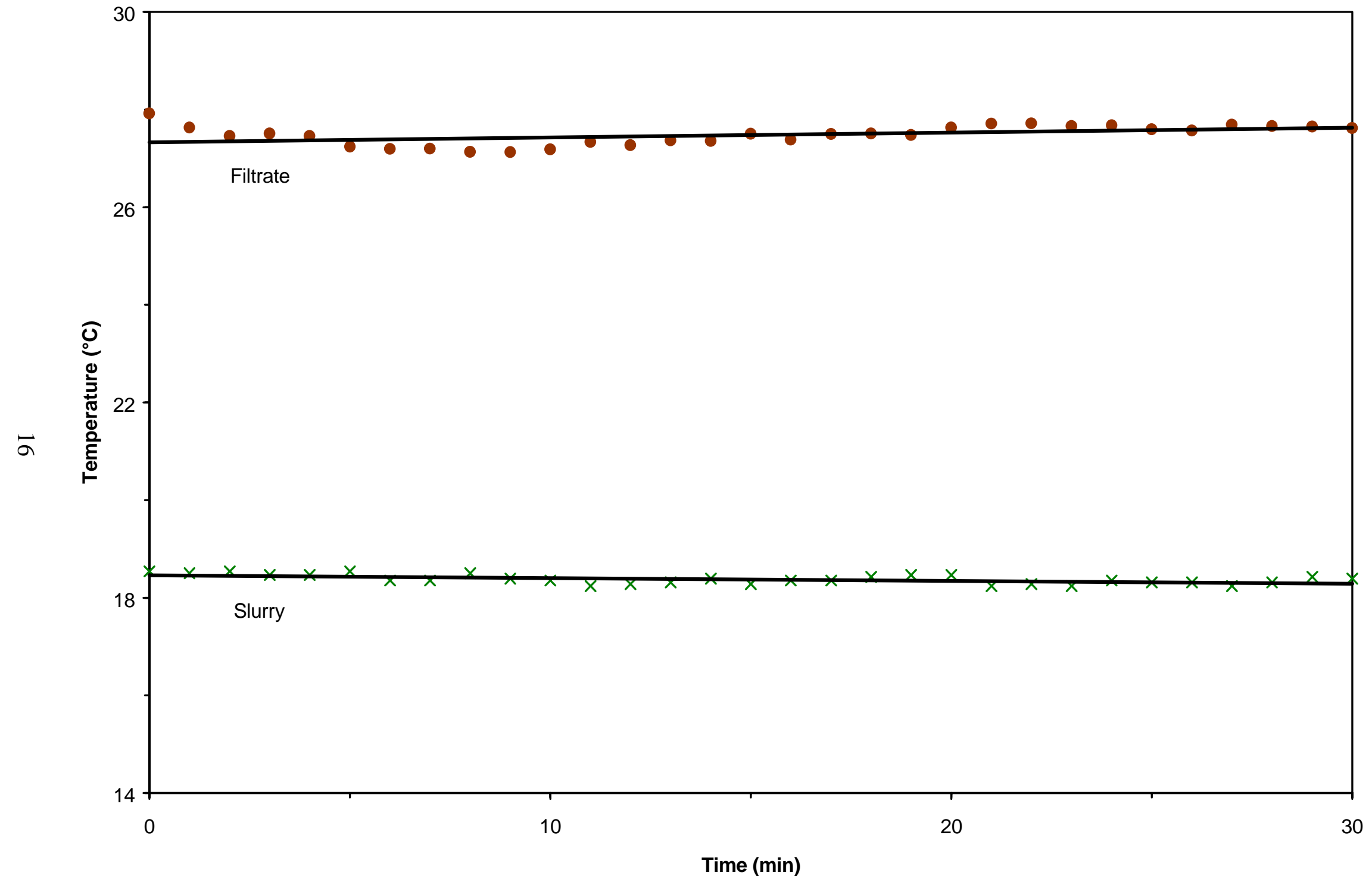

Fig. 6. Plot of slurry and filtrate temperatures for the 30-min evaluation period for the nominal 8 wt $\%$ sample. 
Table 2. Comparison of density data collected with the Coriolis meters as a function of time

\begin{tabular}{|c|c|c|c|c|c|c|c|c|c|c|c|c|c|}
\hline \multirow{3}{*}{$\begin{array}{c}\text { Data } \\
\text { collection } \\
\text { date }\end{array}$} & \multirow{3}{*}{$\begin{array}{c}\text { Number } \\
\text { of data } \\
\text { points }^{a}\end{array}$} & \multicolumn{6}{|c|}{ Coriolis meter for slurry } & \multicolumn{6}{|c|}{ Coriolis meter for filtrate } \\
\hline & & \multicolumn{2}{|c|}{ Density $(\mathrm{g} / \mathrm{mL})$} & \multicolumn{2}{|c|}{ Temperature $\left({ }^{\circ} \mathrm{C}\right)^{b}$} & \multicolumn{2}{|c|}{ Mass flow $(\mathrm{kg} / \mathrm{s})^{c}$} & \multicolumn{2}{|c|}{ Density $(\mathrm{g} / \mathrm{mL})$} & \multicolumn{2}{|c|}{ Temperature $\left({ }^{\circ} \mathrm{C}\right)^{b}$} & \multicolumn{2}{|c|}{ Mass flow $(\mathrm{kg} / \mathrm{s})^{c}$} \\
\hline & & Average & Std. dev. & Average & Std. dev. & Average & Std. dev. & Average & Std. dev. & Average & Std. dev. & Average & Std. dev \\
\hline $1 / 16 / 00$ & 240 & 1.0035 & 0.0001 & 14.1 & 0.1 & -0.0038 & 0.0001 & 1.0001 & 0.0000 & 12.3 & 0.1 & -0.0006 & 0.0000 \\
\hline $2 / 16 / 00$ & 180 & 1.0038 & 0.0000 & 17.8 & 0.1 & -0.0037 & 0.0002 & 0.9997 & 0.0001 & 15.5 & 0.2 & -0.0006 & 0.0000 \\
\hline $2 / 24 / 00$ & 240 & 1.0756 & 0.0021 & 16.5 & 0.1 & -0.0043 & 0.0001 & 1.0225 & 0.0001 & 15.7 & 0.1 & -0.0006 & 0.0000 \\
\hline $2 / 28 / 00$ & 47 & 1.0446 & 0.0015 & 9.3 & 0.1 & 2.2561 & 0.3023 & 1.0243 & 0.0001 & 15.9 & 0.3 & 0.3051 & 0.0006 \\
\hline $4 / 07 / 00$ & 240 & 1.0290 & 0.0006 & 16.9 & 0.1 & 2.3278 & 0.7540 & 1.0209 & 0.0002 & 25.7 & 0.3 & 0.3091 & 0.0011 \\
\hline $4 / 17 / 00$ & 240 & 1.0268 & 0.0001 & 25.0 & 0.5 & -0.0044 & 0.0001 & 0.9993 & 0.0006 & 24.0 & 0.7 & -0.0005 & 0.0000 \\
\hline
\end{tabular}

${ }^{a}$ Data were recorded at 1 -min intervals.

${ }^{c}$ Negative values for mass flow indicate that there was no flow through the instrument. The value shown is an instrumentation offset. 
The standard deviation values for density in the case of the slurry-monitoring meter were higher when slurry was flowing through the instrument. This is probably a result of the heterogeneity of the slurry rather than an inaccuracy of the instrument. Likewise, the standard deviation for the mass flow measurement when slurry was flowing through the instrument is an indication of the variation in flow rate through the instrument.

The standard deviation values for density in the case of the filtrate-monitoring meter were relatively consistent regardless of whether the flow was static or dynamic. This finding can be attributed to the relative homogeneity of the carrier fluid. The standard deviation of mass flow for the filtrate-monitoring meter was slightly higher when the flow was dynamic, possibly due to the temperature change of the filtrate (heat input from recirculating fluid with centrifugal pump). Because of the low values, this variation should not be of much concern. The last density data point for the filtrate monitor in Table 2 showed a slightly higher standard deviation, probably as a result of temperature variation.

\subsection{COMPARISON WITH SUSPENDED SOLIDS ANALYSIS}

The results from the laboratory analyses for density and suspended solids concentration are shown in Table 3. The density and suspended solids concentration data obtained with the dual Coriolis meters are also shown in Table 3. Figure 7 provides a comparison of the suspended solids concentrations from the two methods. Ideally, a linear regression for this comparison would have a slope of 1 and a y-intercept of 0 . The data shows that the actual slope was 1.353, with a bias of 0.134 . The multiple correlation statistic $\left(\mathrm{R}^{2}=0.995\right)$ for the fitted line shows that the data are consistent. A t-test performed on the data indicates that the bias was statistically insignificant at the 5\% level. The density values for the undissolved solids were determined by laboratory analysis and found to be $2.289 \mathrm{~g} / \mathrm{mL}$ for the nominal $6 \mathrm{wt} \%$ sample and $2.360 \mathrm{~g} / \mathrm{mL}$ for the nominal $8 \mathrm{wt} \%$ sample. The solids density for the nominal $2 \mathrm{wt} \%$ sample was not determined because of insufficient sample.

Figure 8 shows a comparison of the density results obtained by laboratory analysis with those from the two Coriolis meters. Again, a linear regression of the slurry density data would have an ideal slope of 1 and a y-intercept of 0 . The linear-regressed slope and y-intercept of the 
Table 3. Comparison of results from grab samples with those obtained by using dual Coriolis meters

\begin{tabular}{|c|c|c|c|c|c|c|c|c|c|c|}
\hline \multirow[b]{3}{*}{ Sample } & \multicolumn{5}{|c|}{ Grab sample results } & \multicolumn{5}{|c|}{ Coriolis meter results } \\
\hline & \multicolumn{2}{|c|}{ Filtrate } & \multicolumn{3}{|c|}{ Slurry } & \multicolumn{2}{|c|}{ Filtrate } & \multicolumn{3}{|c|}{ Slurry } \\
\hline & $\begin{array}{l}\text { Density }^{a} \\
(\mathrm{~g} / \mathrm{mL})\end{array}$ & $\begin{array}{c}\text { Temperature }^{b} \\
\left({ }^{\circ} \mathrm{C}\right)\end{array}$ & $\begin{array}{l}\text { Density }^{a} \\
(\mathrm{~g} / \mathrm{mL})\end{array}$ & $\begin{array}{c}\text { Temperature }^{b} \\
\left({ }^{\circ} \mathrm{C}\right)\end{array}$ & $\begin{array}{c}\mathrm{TSS}^{c} \\
(\mathrm{wt} \%)\end{array}$ & $\begin{array}{l}\text { Density } \\
(\mathrm{g} / \mathrm{mL})\end{array}$ & $\begin{array}{c}\text { Temperature } \\
\left({ }^{\circ} \mathrm{C}\right)\end{array}$ & $\begin{array}{l}\text { Density } \\
(\mathrm{g} / \mathrm{mL})\end{array}$ & $\begin{array}{c}\text { Temperature } \\
\left({ }^{\circ} \mathrm{C}\right)\end{array}$ & $\begin{array}{c}\mathrm{TSS} \\
(\mathrm{wt} \%)\end{array}$ \\
\hline 1 & 1.030 & 25.5 & 1.043 & 25.5 & 1.97 & 1.022 & 25.5 & 1.039 & 18.0 & $2.96^{d}$ \\
\hline 2 & 1.026 & 19.0 & 1.058 & 19.0 & 4.38 & 1.020 & 27.7 & 1.057 & 18.7 & $6.29^{d}$ \\
\hline 3 & 1.026 & 18.0 & 1.070 & 18.0 & 6.03 & 1.022 & 27.5 & 1.072 & 18.4 & $8.15^{e}$ \\
\hline
\end{tabular}

${ }^{a}$ The reported error band is $\pm 1 \%$.

${ }^{b}$ This is the temperature at which the grab sample was analyzed.

${ }^{c}$ TSS $=$ total suspended solids concentration. The reported error band for this analysis is $\pm 10 \%$.

${ }^{d}$ This value is calculated from Eq. (1) with $D 2=2.289 \mathrm{~g} / \mathrm{mL}$.

${ }^{e}$ This value is calculated from Eq. (1) with $D 2=2.360 \mathrm{~g} / \mathrm{mL}$. 


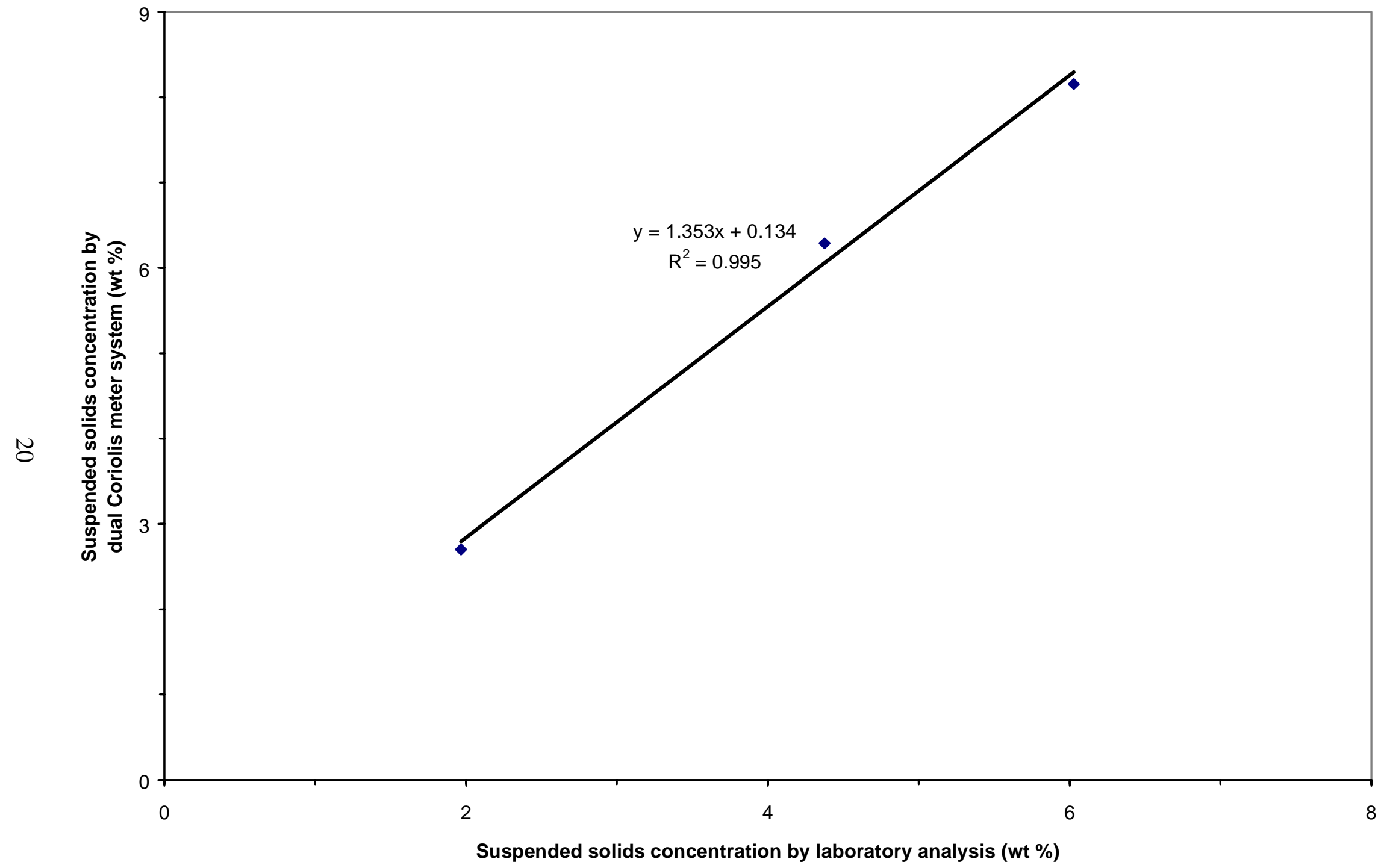

Fig. 7. Comparison of suspended solids concentration determined by laboratory analysis with that obtained by using dual Coriolis meters. 


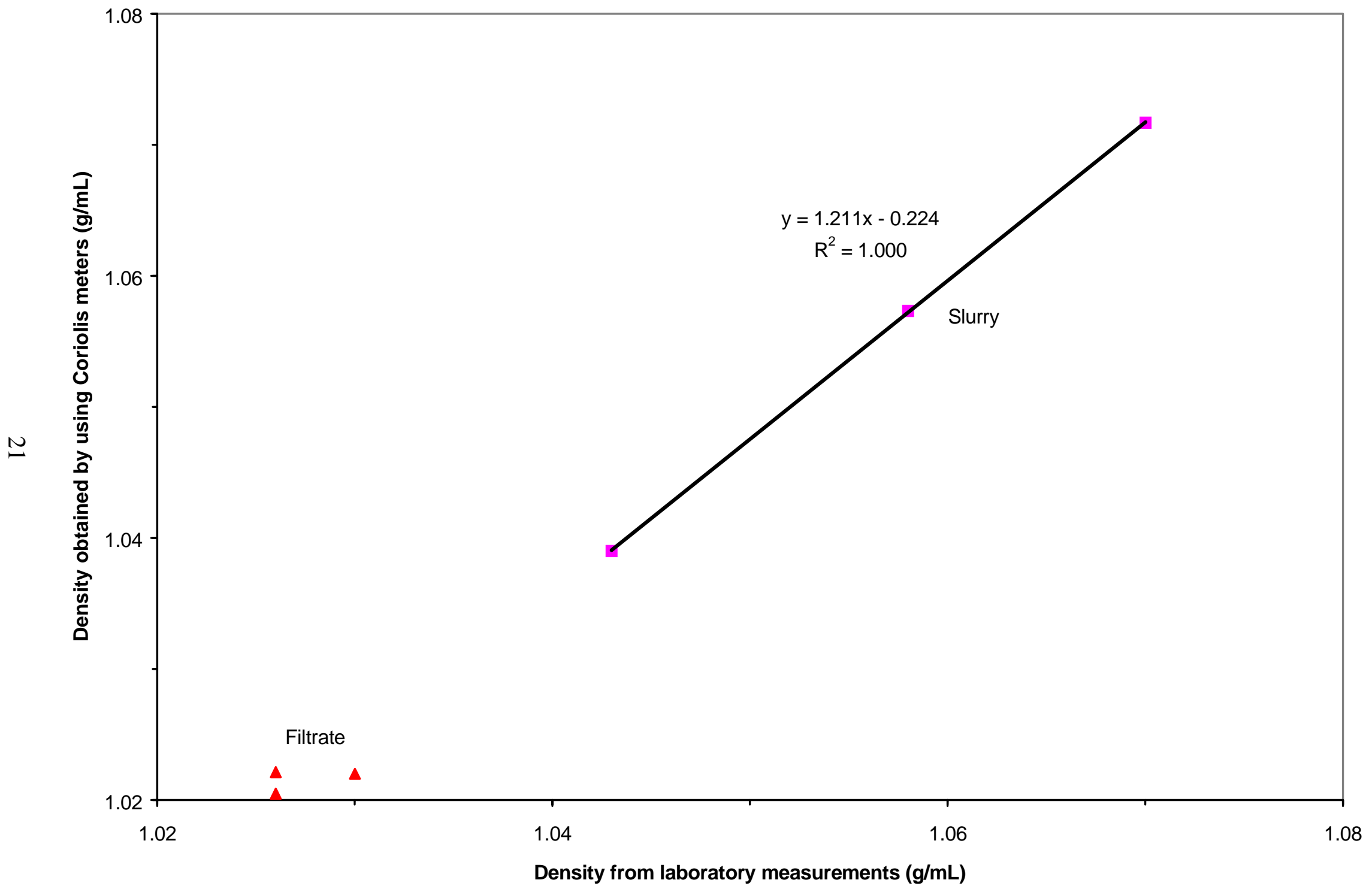

Fig. 8. Comparison of density data determined by laboratory analysis with that obtained by using Coriolis meters. 
line in Fig. 8 are 1.211 and -0.224 , respectively. The multiple correlation coefficient $\left(\mathrm{R}^{2}=\right.$ 1.000) for the linear-regressed line shows that the slurry data are consistent. The filtrate density remained essentially constant during the testing and is best represented by the arithmetic average.

The suspended solids concentration determined by Eq. (1) does not compensate for temperature difference. The equation for compensating for temperature difference, which is shown in Appendix A, requires inputting the volumetric expansion coefficients for the filtrate and the target material. These data are not readily available for the actual waste components. For evaluation purposes, the volumetric expansion coefficients for water and calcium carbonate, which are the primary constituents of the liquid and undissolved solids phases, were used to estimate the effect on suspended solids concentration caused by temperature difference. The results showed that compensating the suspended solids concentration for temperature reduced the suspended solids concentration by $0.05 \mathrm{wt} \%$; therefore, this does not explain the difference between the results obtained by using the dual Coriolis meter system and the laboratory analyses.

\subsection{SUSPENDED SOLIDS CONCENTRATION FROM LABORATORY DENSITY MEASUREMENTS}

The differences in the laboratory and Coriolis meter density results (Table 3) for the filtrate and slurry are relatively minor; however, even minor differences in density can significantly affect the calculation of the concentration of suspended solids. The intent was for the laboratory to analyze the densities at the same temperature that was used in evaluations made with the Coriolis meters; however, this was not always possible.

The laboratory measurements of density were adjusted to compensate for the temperature difference between the grab sample and the respective Coriolis meter and then used in Eq. (1) to calculate the concentration of suspended solids. The temperature-compensated density results for the grab sample and the calculated suspended solids concentration are shown in Table 4, along with the suspended solids concentration determined with the dual Coriolis meter system. A plot of the suspended solids concentration as determined from laboratory density measurements versus the laboratory analysis of suspended solids concentration is shown in 
Table 4. Suspended solids concentration determined from density measurements from laboratory analysis as compared with the results obtained by using the Coriolis meters

\begin{tabular}{|c|c|c|c|c|c|c|c|c|c|}
\hline \multirow[b]{3}{*}{ Sample } & \multicolumn{3}{|c|}{ Grab sample results } & \multicolumn{5}{|c|}{ Coriolis meter results } & \multirow[b]{3}{*}{$\begin{array}{c}\text { TSS } \\
\text { (\% difference) }\end{array}$} \\
\hline & \multirow{2}{*}{$\begin{array}{c}\text { Filtrate } \\
\begin{array}{c}\text { Density }^{a} \\
(\mathrm{~g} / \mathrm{mL})\end{array}\end{array}$} & \multicolumn{2}{|c|}{ Slurry } & \multicolumn{2}{|c|}{ Filtrate } & \multicolumn{3}{|c|}{ Slurry } & \\
\hline & & $\begin{array}{l}\text { Density }^{a} \\
(\mathrm{~g} / \mathrm{mL})\end{array}$ & $\begin{array}{c}\text { TSS } \\
(\text { wt \%) }\end{array}$ & $\begin{array}{l}\text { Density } \\
(\mathrm{g} / \mathrm{mL})\end{array}$ & $\begin{array}{c}\text { Temperature } \\
\left({ }^{\circ} \mathrm{C}\right)\end{array}$ & $\begin{array}{l}\text { Density } \\
(\mathrm{g} / \mathrm{mL})\end{array}$ & $\begin{array}{c}\text { Temperature } \\
\left({ }^{\circ} \mathrm{C}\right)\end{array}$ & $\begin{array}{c}\text { TSS } \\
(\text { wt \%) }\end{array}$ & \\
\hline 1 & 1.030 & 1.045 & $2.57^{b}$ & 1.022 & 25.5 & 1.039 & 19.0 & $2.96^{b}$ & 15.2 \\
\hline 2 & 1.024 & 1.058 & $5.85^{b}$ & 1.020 & 27.7 & 1.057 & 18.7 & $6.29^{b}$ & 7.5 \\
\hline 3 & 1.024 & 1.070 & $7.63^{c}$ & 1.022 & 27.5 & 1.072 & 18.4 & $8.15^{c}$ & 6.8 \\
\hline
\end{tabular}

${ }^{a}$ The density values shown are from Table 3 after adjustment to compensate for temperature differences.

${ }^{b}$ The total suspended solids (TSS) concentration is calculated from Eq. (1) with the listed filtrate and slurry densities and $D 2=2.289 \mathrm{~g} / \mathrm{mL}$.

${ }^{c}$ The total suspended solids (TSS) concentration is calculated from Eq. (1) with the listed filtrate and slurry densities and $D 2=2.360 \mathrm{~g} / \mathrm{mL}$. 
Fig. 9. A linear regression of these data had a slope of 1.240 and a bias of -0.106 . The data remained consistent as evidenced by the $\mathrm{R}^{2}$ value of 0.997 .

\subsection{TEMPERATURE ADJUSTMENT OF DENSITY DATA}

As previously discussed, the filtrate was collected in a holding tank and continuously recirculated to ensure a homogeneous feed stream to the cesium removal and volume reduction operations. Recirculation of the fluid caused a temperature increase. Because density is dependent on temperature, it is reasonable to assume that this increase would introduce error into the real-time measurement of the suspended solids concentration since the temperatures for the slurry density and the filtrate density were different. This factor was evaluated by adjusting the filtrate density values to those that would be obtained if the temperature of the filtrate was assumed to match that of the slurry. The suspended solids concentration was then recalculated from the slurry density, the temperature-compensated filtrate density, and the undissolved solids density with Eq. (1). The results are plotted in Fig. 10 versus the determination of suspended solids with the laboratory's density measurements. Figure 10 also shows a comparison of the results compared with the results without temperature compensation for the filtrate. The slope of the linear regression decreased from 1.062 to 1.000 because of the density adjustment.

\subsection{SURROGATE ANALYSIS}

In order to get a better understanding of the difference between the results obtained with the dual Coriolis meter system and the laboratory data, two surrogate samples were prepared using known quantities of calcium carbonate $\left(\mathrm{CaCO}_{3}\right)$ and sodium nitrate $\left(\mathrm{NaNO}_{3}\right)$ to represent undissolved solids and dissolved solids, respectively. Deionized water was used for the fluid. After being mixed, the samples were sent to the analytical laboratory to determine TSS concentration, slurry density, filtrate density, and density of dry, undissolved solids by the same methods used for the radioactive samples. The physical data for the makeup of these two samples are shown in Table 5; the analytical results for the samples are shown in Table 6.

The analytical results provide some important insights. The sample analyses for TSS concentration match the theoretical concentrations quite well ( $<1 \%$ difference). However, when 


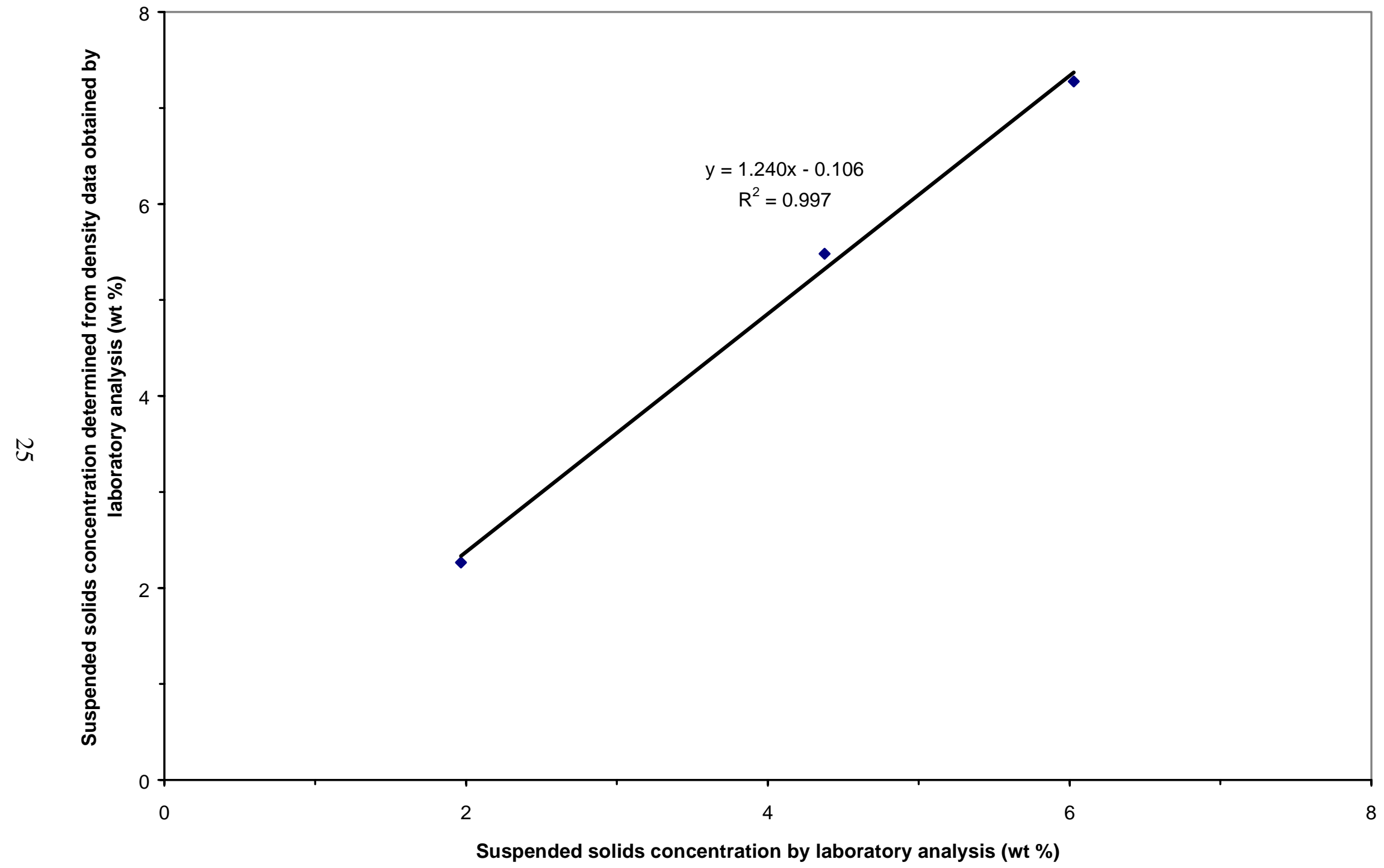

Fig. 9. Comparison of suspended solids concentration determined from density data obtained by laboratory analysis with the suspended solids concentration determined by laboratory analysis. 


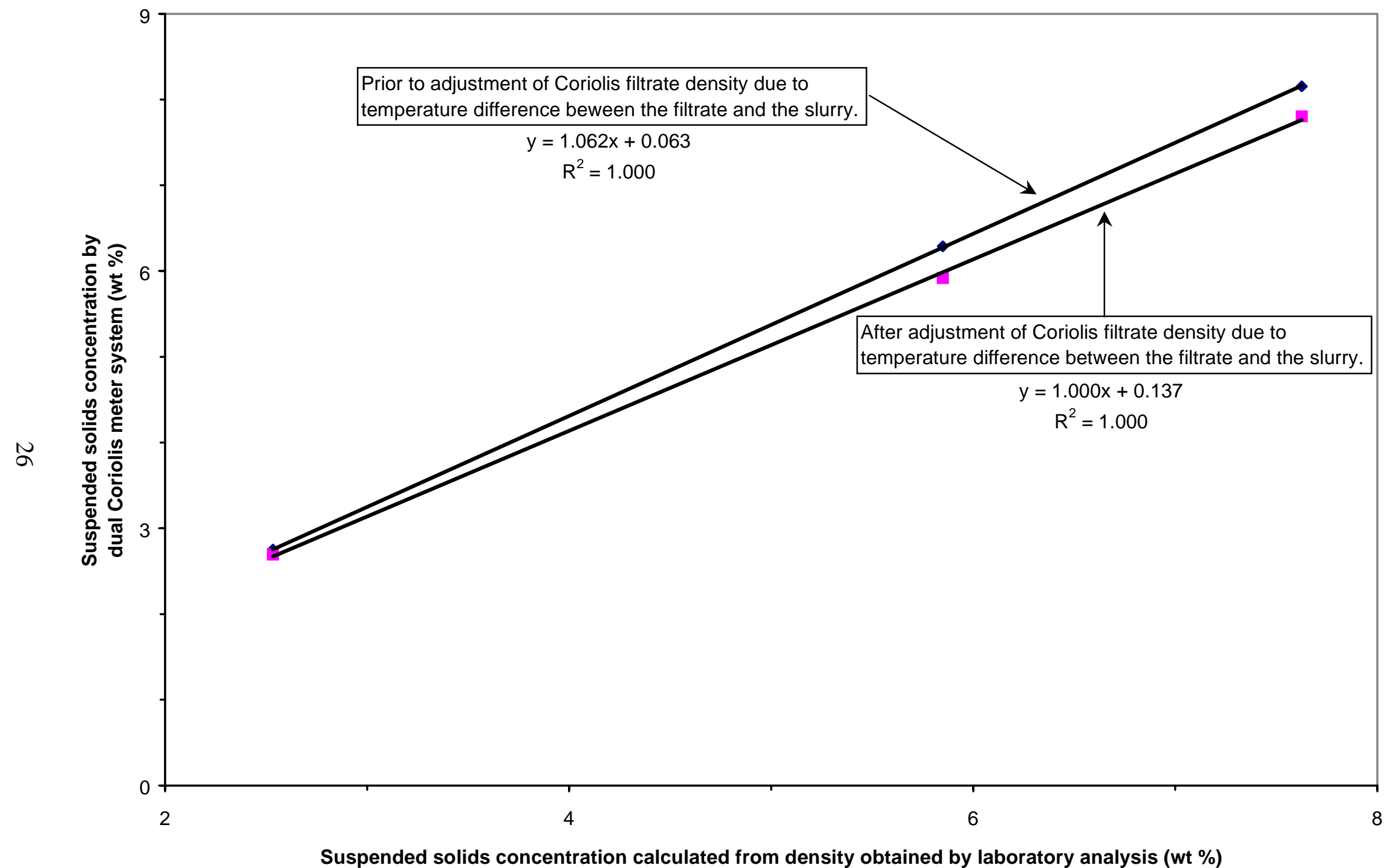

Fig. 10. Comparison of suspended solids concentration determined from laboratory measurement of density (after adjustment due to temperature difference) with that obtained by using the Coriolis meters. 
Table 5. Physical property data for surrogate samples

\begin{tabular}{|c|c|c|c|c|c|c|}
\hline \multirow[b]{2}{*}{ Sample } & \multicolumn{3}{|c|}{ Constituent weight (g) } & \multirow{2}{*}{$\begin{array}{l}\operatorname{TSS}^{a} \\
\text { theoretical conc. } \\
(\text { wt } \%)\end{array}$} & \multirow{2}{*}{$\begin{array}{l}\mathrm{TDS}^{b} \\
\text { theoretical conc. } \\
\text { (wt } \% \text { ) }\end{array}$} & \multirow{2}{*}{$\begin{array}{l}\mathrm{TS}^{c} \\
\text { theoretical conc. } \\
(\mathrm{wt} \%)\end{array}$} \\
\hline & $\mathrm{CaCO}_{3}$ & $\mathrm{NaNO}_{3}$ & Water & & & \\
\hline 1 & 3.0178 & 4.0403 & 93.1338 & 3.01 & 4.03 & 7.04 \\
\hline 2 & 7.1784 & 4.0426 & 92.8985 & 6.89 & 3.88 & 10.78 \\
\hline
\end{tabular}

${ }^{a}$ TSS $=$ total suspended solids.

${ }^{b} \mathrm{TDS}=$ total dissolved solids

${ }^{c} \mathrm{TS}=$ total solids.

Table 6. Surrogate sample results and data analyses

\begin{tabular}{|c|c|c|c|c|c|c|c|c|}
\hline \multirow{2}{*}{ Sample } & \multicolumn{3}{|c|}{ Density (g/mL) } & \multirow{2}{*}{$\begin{array}{l}\text { TSS by } \\
\text { laboratory } \\
\text { analysis } \\
(\mathrm{mg} / \mathrm{L})\end{array}$} & \multirow{2}{*}{$\begin{array}{l}\text { TSS by } \\
\text { laboratory } \\
\text { analysis }^{a} \\
(\mathrm{wt} \%)\end{array}$} & \multirow{2}{*}{$\begin{array}{l}\text { Comparison with } \\
\text { theoretical } \\
\text { concentration }^{b} \\
\text { (wt } \%)\end{array}$} & \multirow{2}{*}{$\begin{array}{c}\text { TSS } \\
\text { calculated } \\
\text { from Eq. (1) } \\
\quad(w t \%)\end{array}$} & \multirow{2}{*}{$\begin{array}{l}\text { Comparison with } \\
\text { theoretical } \\
\text { concentration }^{c} \\
\text { (\% difference) }\end{array}$} \\
\hline & Slurry & Filtrate & Solids & & & & & \\
\hline 1 & 1.047 & 1.030 & 2.460 & 31600 & 3.01 & 0.07 & 2.79 & 7.27 \\
\hline 2 & 1.077 & 1.030 & 2.454 & 74600 & 6.95 & 0.85 & 7.52 & 9.08 \\
\hline
\end{tabular}

${ }^{a}$ The TSS concentration is reported in units of $\mathrm{mg} / \mathrm{L}$. The units are converted to wt $\%$ by multiplying the reported value by $\left[1 /\left(\right.\right.$ density $\left.\left.\times 10^{6}\right)\right]$.

${ }^{b}$ This column compares the TSS results from laboratory analysis with the theoretical concentrations shown in Table 5.

${ }^{c}$ This column compares the TSS values calculated from Eq. (1) with the theoretical concentrations shown in Table 5. 
the density values are used to calculate the TSS concentration with Eq. (1), these results do not compare as well (i.e., 7-9\% difference). Note that the results for sample 1 underpredict the theoretical concentration and the results for sample 2 overpredict it.

It is believed that the difference between the theoretical concentration and that obtained from the calculated concentration from Eq. (1) can be attributed to the sensitivity of Eq. (1) to the density values. The following examples illustrate this point.

The slurry density can be calculated from Eq. (1) by using the theoretical TSS concentration and the laboratory-reported density values for the filtrate and dry, undissolved solids. When this calculation is performed for the two surrogate samples, the results indicate values of 1.048 and $1.073 \mathrm{~g} / \mathrm{mL}$, respectively. These values represent differences of 0.001 and $0.004 \mathrm{~g} / \mathrm{mL}$ as compared with the laboratory measurements of slurry density. Thus, small changes in the slurry density could apparently make significant changes in the TSS concentration calculated by Eq. (1). This sensitivity helps explain the differences between the theoretical values and the calculated values and is likely also a contributor in the radioactive sample analyses.

A similar sensitivity analysis can be done for the filtrate density using the theoretical TSS concentration and the laboratory measurements for densities of the slurry and the dry, undissolved solids. The results show that 1.029 and $1.034 \mathrm{~g} / \mathrm{mL}$ are obtained for the two filtrate densities, respectively, which represent differences of 0.001 and $0.004 \mathrm{~g} / \mathrm{mL}$ as compared with the laboratory measurements. These data also show that Eq. (1) is sensitive to the filtrate density and also help explain the differences between the theoretical and calculated TSS concentrations.

A sensitivity analysis was performed for the density of the dry, undissolved solids in a similar manner. The densities of the dry, undissolved solids were calculated from Eq. (1) using the theoretical TSS concentration and the laboratory measurements for slurry and filtrate densities. The calculated values were 2.235 and $2.806 \mathrm{~g} / \mathrm{mL}$, which represent differences of 0.225 and $0.352 \mathrm{~g} / \mathrm{mL}$, respectively. These results show that the TSS calculation from Eq. (1) is not as sensitive to the density of the dry, undissolved solids as it is to the densities of the slurry and the filtrate. 


\section{CONCLUSIONS AND RECOMMENDATIONS}

ORNL is treating liquid low-level waste for volume reduction and cesium removal. To prevent fouling of the unit operations, the feed stream from the waste storage tanks is first treated with a filtration system (i.e., SLS system) for removal of undissolved solid particles. Operations personnel initially used a Coriolis meter to monitor the density of the feed stream to the SLS system, and the concentration of suspended solids was then determined from the measured feed stream density and assumed values for the densities of the carrier fluid and the undissolved solids. In the project described here, the assumption of the carrier fluid density was eliminated by installing a second Coriolis meter in the SLS system to monitor the density of the filtrate. When the suspended solids concentration reached the preset limit, the treatment operations for that particular tank were discontinued to prevent plugging of the SLS system. This project successfully installed and deployed a dual Coriolis meter system to monitor the suspended solids concentration in a radioactive slurry. The SLS system, which was a cross-flow filtration system, used sintered-metal tubes that were rated to remove particles as small as $0.5 \mu \mathrm{m}$. The suspended solids concentration was calculated from the density of the slurry, density of the carrier fluid (i.e., filtrate), and an assumed constant value for the density of the dry, undissolved solids with Eq. (1). An evaluation of the dual Coriolis meter system was determined by collecting data for comparison with the results obtained from grab-sample analyses.

It should be noted that the presence of a bias does not mean that the instrument has failed. When an instrument exhibits a bias, it can be calibrated to offset the bias. A comparison of the suspended solids concentration as reported by the dual Coriolis meter system with the results obtained by laboratory analysis of grab samples indicates that the values were slightly higher than the laboratory results. A linear relationship existed between the two methods, which indicates that the bias was proportional to the concentration of suspended solids.

One contributing factor to the discrepancy between the results from the laboratory and the dual Coriolis meter system is the small difference between the density of the carrier fluid and the density of the slurry (an indication of low suspended solids concentration). It was also shown that the equation for calculating the suspended solids concentration from the relationships between the densities of the slurry, filtrate, and dry, undissolved solids was quite sensitive to changes in the slurry density and the filtrate density and, to a lesser extent, the density of the dry, 
undissolved solids. Since density measurement is dependent on composition and temperature, these process parameters need to be controlled in order to obtain more accurate results.

Other potential contributors to the difference between the data from the laboratory and results from the dual Coriolis meter system are the assumptions that the density of the dry, undissolved solid particles is known and constant. In this study, these values were determined by laboratory analysis. The density of the dry, undissolved solids was determined for two samples, and the results show that either the density was not constant or there was some variance in the analyses. However, these analyses were performed on a single analysis (i.e., no replicates) per sample; thus it is not known how much variance is in the analysis.

There is also some potential difference due to the fact that the undissolved solids are moisture laden (in the slurry). The density of the undissolved solids is determined on a dry basis. When the solids are in contact with the carrier fluid, they absorb liquid into pores that were previously filled with air. If one assumes that the particle volume remains constant, then the density of the solid particles would have to increase proportionally. However, it is also possible that the volume of the particle changes as the particle absorbs the liquid (e.g., it swells), and the density is thereby changed by the absorbed mass and the change in volume. Discussions with analytical chemistry personnel confirmed that it would be very difficult to obtain accurate and repeatable density measurements for moisture-laden particles.

An analysis of the electronic data shows that the precision, as defined by the standard deviation of the data, was very good. The standard deviations for the density measurements of the slurry and filtrate were $\leq 0.0005$ and $\leq 0.0002 \mathrm{~g} / \mathrm{mL}$, respectively. When the density data were converted to suspended solids concentration, the standard deviation was $\leq 0.08$ wt $\%$. Electronic data that were collected over the course of the project show that the precision remained at these levels over time.

A draft copy of this report was provided to an Endress + Hauser representative for review and comment. The representative was requested to provide a written response to the results and conclusions presented in this report. A copy of the response from the representative is included in Appendix B.

The following items are recommendations for implementation of a dual Coriolis meter system at other sites. 
1. An on-site calibration of the Coriolis meters should be performed with the actual slurries and filtrates. This task would probably require the installation of a recirculation loop; however, the sites may have a recirculation loop configured in their design to determine the concentration of suspended solids prior to beginning a cross-site transfer. So, no extra costs would be incurred except for analyses of the calibration samples. The calibration samples should be analyzed by the same reference laboratory (if possible, by the same analyst) as would be used for future verification samples. If possible, the Coriolis meter for monitoring the slurry should be tested with at least three concentrations of suspended solids (one of the tests should be just carrier fluid).

2. The laboratory analyses should be performed at the same temperature that the data from the Coriolis meters were obtained.

3. The temperature differences between the slurry and filtrate streams should be minimized. In the case of the SLS system, it would have probably been better if the Coriolis meter for the filtrate had been installed prior to the filtrate holding tank, but this was not possible as the meter was retrofitted into the system.

4. The density of the undissolved solid particles should be determined beforehand to provide an accurate value for the use of that parameter in Eq. (1). Multiple analyses should be performed on the same sample to establish the parameter range. 


\section{REFERENCES}

1. T. D. Hylton et al., Comparative Testing of Slurry Monitors, ORNL/TM-13587, Oak Ridge National Laboratory, Oak Ridge, Tennessee, May 1998.

2. B. A. Reynolds et al., Instrument Validation Facility, PNNL-11221, Pacific Northwest National Laboratory, Richland, Washington, 1996.

3. E. A. Daymo et al., "Acceptance Testing of the Lasentec Focused Beam Reflectance Measurement (FBRM) Monitor for Slurry Transfer Applications at Hanford and Oak Ridge," in Proceedings of the SPIE Conference on Nuclear Waste Instrumentation and Engineering, SPIE Vol. 3536, Boston, November 1998.

4. J. R. Bontha et al., Qualification of the Lasentec M600P Particle Size Analyzer and the Red Valve Model 1151 Pressure Sensor, PNNL-13064, Pacific Northwest National Laboratory, Richland, Washington, January 2000.

5. T. D. Hylton and C. K. Bayne, Testing of In-Line Slurry Monitors and Pulsair Mixers with Radioactive Slurries, ORNL/TM-1999/111, Oak Ridge National Laboratory, Oak Ridge, Tennessee, July 1999.

6. T. E. Kent et al., Development and Deployment of a Full-Scale Cross-Flow Filtration System for Treatment of Liquid Low-Level Waste at Oak Ridge National Laboratory, ORNL/TM-2000/27, Oak Ridge National Laboratory, Oak Ridge, Tennessee, 2000.

7. J. F. Walker, Jr., et al., Cesium Removal Demonstration Utilizing Crystalline Silicotitanate Sorbent for Processing Melton Valley Storage Tank Supernate: Final Report, ORNL/TM13503, Oak Ridge National Laboratory, Oak Ridge, Tennessee, 1998.

8. J. F. Walker, Jr., et al., Wastewater Triad Project: Solid-Liquid Separations FY 2000 Deployment, ORNL/TM-2000/186, Oak Ridge National Laboratory, Oak Ridge, Tennessee, to be published.

9. "Standard Test Method for Specific Gravity and Density of Semi-Solid Bituminous Materials (Pycnometer Method)," ASTM D70-97, American Society for Testing and Materials, West Conshohocken, Pennsylvania, 1997.

10. "Residue, Non-Filterable (Gravimetric, Dries at $103-105^{\circ} \mathrm{C}$ )," EPA 600-160.2, Environmental Protection Agency. 
Appendix A

CALCULATION OF SUSPENDED SOLIDS FROM DENSITY DATA (TEMPERATURE COMPENSATED) 



\section{Suspended Solids Concentration Determined from Density Measurements and with Temperature Compensation}

The equations shown below for determining suspended solids concentration with temperature compensation were provided by Marcel Woiton, of Endress + Hauser, Inc. The equations are generic for two-phase mixtures and can be used for liquid-liquid mixtures (e.g., alcohol and water) as well as for liquid-solid mixtures.

$$
\operatorname{Mass} \%=\frac{\frac{D 2 \times \rho}{[1+(a 2 \times \Delta t)]}-\frac{D 2 \times D 1}{[1+(a 2 \times \Delta t)] \times[1+(a 1 \times \Delta t)]}}{\frac{D 2 \times \rho}{[1+(a 2 \times \Delta t)]}-\frac{D 1 \times \rho}{[1+(a 1 \times \Delta t)]}} \times 100
$$

and

$$
\text { Volume } \%=\frac{\rho-\frac{D 1}{[1+(\alpha 1 \times \Delta t)]}}{\frac{D 2}{[1+(\alpha 2 \times \Delta t)]}-\frac{D 1}{[1+(\alpha 1 \times \Delta t)]}} \times 100 \text {, }
$$

where

$$
\begin{aligned}
\rho & =\text { measured density of medium; } \\
D 1 & =\text { density of carrier fluid; } \\
D 2 & =\text { density of target medium (e.g., dry, undissolved solid particles); } \\
\alpha 1 & =\text { volumetric expansion coefficient of carrier fluid, unit }=\mathrm{K}^{-1},(\mathrm{~K}=\text { kelvin }) ; \\
\alpha 2 & =\text { volumetric expansion coefficient of target medium, unit }=\mathrm{K}^{-1},(\mathrm{~K}=\text { kelvin }) ; \\
\Delta t & =t-t_{n ;} \\
t & =\text { actual measured temperature of medium; } \\
t_{n} & =\text { standard temperature for temperature compensation }(\text { e.g., } 293 \mathrm{~K}) .
\end{aligned}
$$



Appendix B

LETTER OF RESPONSE FROM ENDRESS + HAUSER 



\section{Endress+Hauser}

Endress + Hauser, Inc. • Greenwood, Indiana

August 1, 2000

T. D. Hylton

Oak Ridge National Laboratory

Chemical Technology Division

Radiochemical Technology Section

Building 2528, MS-6330

P.O. Box 2008

Oak Ridge, TN 37831-6330

Re: An Evaluation of a Dual Coriolis Meter System for In-Line Monitoring of Suspended Solids Concentrations in Radioactive Slurries (ORNL/TM-2000/184, June 30, 2000)

Dear Mr. Hylton:

Endress + Hauser is proud to be a part of your continuing investigation into the proper treatment of radioactive sludge wastes. We thank you for your diligent tests and analyses.

After reviewing the above-referenced draft report, we would like to offer the following comments:

1. Overall, we are pleased with the performance of the Promass 63F Coriolis flowmeters in this application. As you indicated, the correlation between the meters and the laboratory data was very strong.

2. You correctly conclude that the effect of temperature differences between slurry and filtrate is indeed significant. To achieve maximum accuracy in the calculation of suspended solids concentration (without applying temperature correction), this temperature difference must be eliminated. As your data proved, the agreement between the Coriolis system and the laboratory data was vastly improved after compensating for the filtrate temperature change. You also offer a valid recommendation that the laboratory analyses should be performed at the same temperature that the data from the Coriolis meters was obtained.

3. Normally, an on-site density calibration of the Coriolis meters can help to improve the measurement accuracy, as you pointed out in your recommendations. Caution should be exercised when performing a density calibration on the slurry meter. The presence of suspended solids can adversely influence the calibration process if the calibration is performed when the slurry is at rest, allowing the solids to fall out of suspension and potentially temporarily imbalance the meter's measuring tubes. Likewise, slurries at rest can potentially cause calibration errors if the slurry 
separates and creates a slurry density value inside the meter that does not truly reflect the density value obtained via laboratory analysis.

Again, we at Endress + Hauser thank you for the excellent work you are doing, and the valuable analysis you are performing. If we can be of further service, please feel free to contact me at any time.

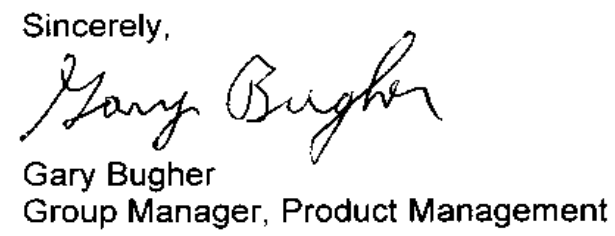


ORNL/TM-2000/184

\section{INTERNAL DISTRIBUTION}

1. C. K. Bayne

2. L. K. Felker

3. M. T. Hurst

4. T. D. Hylton

5. C. M. Kendrick

6. T. E. Kent

7. B. E. Lewis, Jr.

8. C. P. McGinnis

9. L. E. McNeese
10. B. D. Patton

11. S. M. Robinson

12. M. G. Stewart

13. S. D. Van Hoesen

14. J. F. Walker, Jr.

15. ORNL Central Research Library

16. ORNL Laboratory Records-RC

17-18. ORNL Laboratory Records-OSTI

19. REDC Document Center

\section{EXTERNAL DISTRIBUTION}

20. Ron Bafus, Numatec Hanford Co., Box 1300, MSIN: R3-73, Richland, Wash. 99352

21. Glenn Bastiaans, Ames Laboratory, 125 Spedding Hall, Ames, IA 50011-3020

22. J. R. Bontha, Pacific Northwest National Laboratory, P.O. Box 999, MSIN: K6-24, Richland, WA 99352

23. Gary Bugher, Endress + Hauser, Inc., 2350 Endress Place, Greenwood, IN 46143

24. Bob Farmer, Lockheed Martin Energy Systems, P.O. Box 2009, Oak Ridge, TN 37831-8031

25. Pat Fuller, COGEMA Engineering, Mail stop R3-83, P.O. Box 1500, Richland, WA 99352

26. Pete Gibbons, Numatec Hanford Company, P.O. Box 1300, MSIN: K9-91, Richland, WA 99352

27. Joseph M. Ginanni, U.S. Dept. of Energy, Nevada Operations Office, 232 Energy Way, North Las Vegas, NV 89030-4199

28. Daryl Green, U.S. Dept. of Energy, 55 Jefferson, EM93, Oak Ridge, TN 37831-8620

29. William Haas, Ames Laboratory, 125 Spedding Hall, Ames, IA 50011-3020

30. Gary M. Johnson, Westinghouse Savannah River Co., Building 742-4G, Aiken, SC 29808

31. Marshall Johnson, Tetra Tech NUS, 800 Oak Ridge Turnpike, Suite A600, Oak Ridge, TN 37830

32. John Jones, U.S. Dept. of Energy, Nevada Operations Office, 232 Energy Way, North Las Vegas, NV 89030-4199

33. Paula Kirk, Bechtel Jacobs Company LLC, P.O. Box 4699, MS-7604, Oak Ridge, TN 37831-7604

34. Brenda Lewis, Westinghouse Savannah River Company, Bldg. 703H, Rm. 99, Aiken, SC 29808

35. Nick Mann, Bechtel BWXT Idaho, Inc., P.O. Box 1625, MSIN 5218, Idaho Falls, ID 83415-5218

36. Thomas May, Numatec Hanford Co., P.O. Box 1300, MSIN: R3-73, Richland, WA 99352 
37. Charles Nalezny, U.S. Dept. of Energy, EM-53, 19901 Germantown Road, Germantown, MD 20874-1290

38. Jacquie Noble-Dial, U.S. Dept. of Energy, 55 Jefferson, EM93, Oak Ridge, TN 37831-8620

39. Mike Rinker, Pacific Northwest National Laboratory, P.O. Box 999, MSIN: K5-22, Richland, WA 99352

40. Dave Roelant, Hemispheric Center for Environmental Technologies, FIU, 10555 Flagler St., Miami, FL 33174

41. Larry Tavlarides, Syracuse University, Dept. of Chemical Engineering \& Materials Science, 334 Hinds Hall, Syracuse, NY 13244-1190

42. Tom Thomas, Bechtel BWXT Idaho, Inc., P.O. Box 1625, MSIN 3760, Idaho Falls, ID 83415-3760

43. Warren Thompson, CH2MHill, 2419 Michael Ave, Richland, WA 99352

44. Jeffery S. Walker, U.S. Dept. of Energy, EM-53, 19901 Germantown Road, Germantown, MD 20874-1290

45. Paul Wang, Concurrent Technologies Corporation, $4256^{\text {th }}$ Avenue, $28^{\text {th }}$ Floor, Regional Enterprise Tower, Pittsburgh, PA 15238 